\title{
Materials for Solid-Phase Extraction of Organic Compounds
}

\author{
Núria Fontanals *, Rosa M. Marcé(i) and Francesc Borrull \\ Department of Analytical Chemistry and Organic Chemistry, Universitat Rovira I Virgili, Marcel-lí Domingo, 1, \\ Campus Sescelades, Building N4, 43007 Tarragona, Spain; rosamaria.marce@urv.cat (R.M.M.); \\ francesc.borrull@urv.cat (F.B.) \\ * Correspondence: nuria.fontanals@urv.cat; Tel.: +34-977-55-8629
}

Received: 21 October 2019; Accepted: 28 November 2019; Published: 6 December 2019

check for updates

\begin{abstract}
This review provides an overview of the most recent developments involving materials for solid-phase extraction applied to determine organic contaminants. It mainly concerns polymer-based sorbents that include high-capacity, as well as selective sorbents, inorganic-based sorbents that include those prepared using sol-gel technology along with structured porous materials based on inorganic species, and carbon nanomaterials, such as graphene and carbon nanotubes. Different types of magnetic nanoparticles coated with these materials are also reviewed. Such materials, together with their main morphological and chemical features, are described, as are some representative examples of their application as solid-phase extraction materials to extract organic compounds from different types of samples, including environmental water, biological fluids, and food.
\end{abstract}

Keywords: materials; solid-phase extraction; organic compounds; silica; polymeric; carbonaceous; porous; magnetic; (nano)particles; selectivity; capacity

\section{Introduction}

Sample treatment is still one of the main challenges in the development of analytical methods to determine organic compounds from different matrices. Therefore, resourcing from sample preparations that include preconcentration of the compounds and the elimination of matrix interferents is still to be recommended before any chromatographic determination.

Over time, solid-phase extraction (SPE) has emerged as the most commonly used and successful sample extraction technique to extract compounds from liquid matrices effectively. One of its main advantages is its versatility since a wide range of materials that have different properties and types of interaction with the compounds have become available [1].

Silica-based sorbents and those modified with $\mathrm{C}_{18}, \mathrm{C}_{8}$, or $\mathrm{NH}_{2}$ were the first to be applied to SPE. However, they have a number of drawbacks, such as instability at extreme pHs and the activity of residual silanols. Carbon-based sorbents such as graphitized carbon blacks (GCBs) and porous graphitic carbons (PGCs) then emerged, presenting high (and even irreversible) retention of some compounds. Polymer-based sorbents appeared later to overcome the disadvantages of previous sorbents and have remained one of the main developments in SPE, with continuous progress being made over recent decades. Polymeric sorbents combine outstanding morphological properties that promote capacity and retention with tuned chemical properties that allow suitable interactions with many types of compounds and show enhanced stability under several SPE conditions. They might today be described as the most well-established technology for SPE, although several developments with these types of material have also been made with regards to the tuning of their properties, interactions, and fields of application. 
In recent years, however, other developments in sorbent technology apart from those involving polymer-based materials have also taken place. These novel materials include organic-inorganic hybrid materials, metallic nanoparticles, metal-organic frameworks, carbon nanomaterials, among others.

The aim of this review is to provide an overview of the latest developments in sorbent technology for SPE. There are different classifications for presenting these materials, although we organized the present review in accordance with the typical classification of sorbents for SPE that tend to be silica-based, carbon-based, and polymer-based. Nevertheless, novel strategies in morphology and chemistry that have emerged recently are also thoroughly discussed. As the field is very large and promising, we merely describe the materials and their main properties, providing some illustrative examples for each type of material as a representative fraction of the research published in this field. We encourage readers to consult specific reviews of each type of material to learn more about the details of the synthetic approaches used, their characterization, features, and applications.

\section{Polymer-Based Materials}

Polymer based-materials have been one of the main developments in SPE. This is mainly because of their morphological (high specific surface area-SAA- and porosity) and chemical features that result from the diversity of synthetic routes that can be applied, introducing various chemical moieties into the polymer framework. Indeed, although these materials are long-established and have been applied over the years, research in this area is continuously growing. Evidence of this is the fact that several polymeric sorbents are commercially available and widely applied among the scientific community for various applications, including a wide range of compounds extracted from different fields (food, biological, environmental, etc.), together with others that have been developed in-house. Table 1 shows some selected examples of the applications of polymeric-based sorbents. Comprehensive information on the application of these materials can be found in previous reviews and book chapters on the subject [2-5].

Different types of polymer-based sorbents have been developed to accommodate high-capacity or high-selectivity properties, or a combination of both. The following sections describe these and discuss some examples of their applications. 
Table 1. Examples of the applications of polymer-based materials in solid-phase extraction.

\begin{tabular}{|c|c|c|c|c|c|c|}
\hline Type & Material & SPE Mode & Compounds & Sample & Instrumental Technique & Reference \\
\hline \multirow[t]{12}{*}{ High capacity } & PLRP-S & off-line & drugs of abuse & wastewater & LC-MS/MS & [6] \\
\hline & Bond Elut Plexa & dispersive & antibiotic & milk & LC-MS/MS & [7] \\
\hline & Strata $X$ & off-line & pharmaceuticals & wastewater & LC-MS/MS & [8] \\
\hline & Oasis HLB & off-line & sweeteners & wastewater & LC-MS/MS & [9] \\
\hline & Oasis HLB & in-line & drugs & urine & CE-MS & [10] \\
\hline & Lichrolut EN & off-line & $\mathrm{EDCs}^{1}$ & urine, blood, milk & GC-MS & [11] \\
\hline & XAD-4 modif. $\mathrm{NO}_{2} / \mathrm{COCH}_{3} / \mathrm{NH}_{2} / \mathrm{COOH}$ & on-line $\mu \mathrm{SPE}$ & pesticides & urine, oil, wastewater & LC-UV & [12] \\
\hline & PS-DVB modif. benzoyl & on-line & pesticides & river & LC-UV & [13] \\
\hline & NVIm-DVB ${ }^{2}$ & on-line & pesticides & river & LC-UV & [14] \\
\hline & MAA-EDMA ${ }^{3}$ & off-line & nerve agents \& organophosphorus & organic matrix & GC-MS & [15] \\
\hline & HXLPP ${ }^{4}$ & on-line & pesticides & river, wastewater & LC-UV & [16] \\
\hline & HXLPP (HEMA) ${ }^{5}$ & off-line & pesticides & river, wastewater & LC-UV & [17] \\
\hline \multirow[t]{16}{*}{ Selective } & MIP (ciprofloxacin) & off-line & antibiotics & lake, wastewater & LC-MS/MS & [18] \\
\hline & MIP (caffeic acid) & off-line & polyphenols & Oil, wastewater & LC-UV & [19] \\
\hline & MIP (bisphenol A) & off-line & bisphenol A & sediments, milk, oil, urine & LC-DAD & [20] \\
\hline & MIP (insulin) & off-line & insulin & plasma & LC-DAD & [21] \\
\hline & MIP (PAHs) & off-line & PAHs 6 & seawater & GC-MS & [22] \\
\hline & SupelMIP NSAIDs & off-line & NSAIDs $^{7}$ & wastewater & LC-MS/MS & [23] \\
\hline & SupelMIP AG & off-line & aminoglycosides & milk & LC-MS/MS & [24] \\
\hline & AffiMIP-Phenolic & off-line & PCBs $^{8}$, PBDEs $^{9}$ & animal tissues & GC-MS, LC-MS & [25] \\
\hline & Oasis MCX & off-line & drugs of abuse & wastewater, urine & LC-MS/MS & [26] \\
\hline & Strata-X-WC & off-line & toxins & urine & LC-TOF 10 & [27] \\
\hline & Oasis WAX & off-line & PFCAs ${ }^{11}$ & river, groundwater, drinking & LC-MS/MS & [28] \\
\hline & Bond Elut Plexa SAX & off-line & herbicides & stormwater & LC-MS/MS & [29] \\
\hline & HXLPP-WAX ${ }^{4}$ & on-line & pharmaceuticals & river, wastewater & LC-UV & [30] \\
\hline & HXLPP-WCX ${ }^{4}$ & off-line & pharmaceuticals & river, wastewater & LC-MS/MS & [31] \\
\hline & DEAEMA-DVB-SAX ${ }^{12}$ & off-line & pharmaceuticals & urine & LC-UV & [32] \\
\hline & GMA-DVB-SCX ${ }^{13}$ & off-line & alkylate purines & river, wastewater & LC-UV & [33] \\
\hline
\end{tabular}

${ }^{1}$ EDCs: endocrine disrupting compounds; ${ }^{2}$ NVIm-DVB: N-vinylimidazole-divinylbenzene; ${ }^{3}$ MAA-EDMA: methacrylic acid-ethyldimethacrylate; ${ }^{4}$ HXLPP: hyper-crosslinked sorbent prepared by precipitation polymerization; ${ }^{5}$ HXLPP (HEMA): HXLPP including hydroxyethylene dimethacrylate; ${ }^{6}$ PAHs: polycyclic aromatic compounds; ${ }^{7}$ NSAIDs: non-steroidal anti-inflammatory drugs; ${ }^{8}$ PCBs: polychlorinated bisphenyls; ${ }^{9}$ PBDEs: polybrominated diphenyl ethers; ${ }^{10}$ TOF: time-of-flight; ${ }^{11}$ PFCAs: polyfluorinated carboxylic acids; ${ }^{12}$ DEAEMA: 2-(diethylamino)ethyl methacrylate; ${ }^{13}$ GMA: glycidyl methacrylate. 


\subsection{High-Capacity Polymeric Materials}

Conventional polymeric sorbents are crosslinked polymers based on poly(styrene-divinylbenzene) (PS-DVB), which has a hydrophobic structure and SSA of up to $500 \mathrm{~m}^{2} / \mathrm{g}$. The hydrophobic structure of the PS-DVB polymer interacts with the analytes through the Van der Waals forces and $\pi-\pi$ interactions of the aromatic rings. However, the hydrophobic structure shows low retention toward the polar analytes. This can be overcome by introducing polar moieties into the sorbents to promote polar interactions with the analytes and improve retention. The SSA can also be increased (ca. $1000 \mathrm{~m}^{2} / \mathrm{g}$ ) by further crosslinking the polymeric network to obtain hyper-crosslinked (HXL) polymers, which show enhanced retention capacity.

Hydrophilicity can be introduced by chemically modifying the hydrophobic polymer (i.e., PS-DVB) with polar functional groups or by copolymerizing with polar monomers. Figure 1 shows the typical synthetic approach used to obtain hydrophilic polymeric sorbents through chemical modification (A) and copolymerization (B).

A)

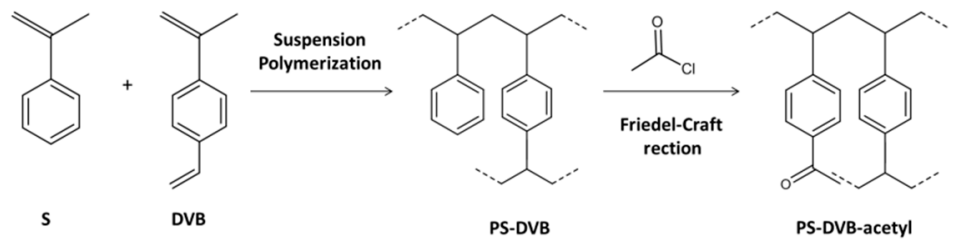

B)



Figure 1. Synthetic approaches to prepare hydrophilic polymeric sorbents: by chemical modification (A) and by copolymerization with a hydrophilic monomer (B).

With regard to the chemical functionalization approach, the PS-DVB polymeric network is chemically modified with a polar moiety framed in a Friedel-Craft reaction. Using this approach, polymeric materials with optimal morphological features can be obtained from the precursor. Strata- $X$ (Phenomenex) is a commercially available sorbent based on PS-DVB functionalized with pyrrolidone moieties that confer hydrophilic properties. In one application, Strata- $X$ was applied to extract a group of pharmaceuticals from wastewater in combination with liquid chromatography (LC) followed by mass spectrometry in tandem (MS/MS), achieving satisfactory results in terms of recovery $(50-117 \%)$ and low matrix effect (-30-30\%) [8]. A PS-DVB polymer was functionalized with a benzoyl moiety in order to give the obtained sorbent polar properties while maintaining the same morphological properties (i.e., SSA $900 \mathrm{~m}^{2} / \mathrm{g}$ ). Packed in the on-line SPE followed by LC with UV detection (LC-UV), this sorbent successfully applied to extract a group of pesticides in river water and achieved better results than those obtained with the non-modified resin [13]. Recently, XAD-4 resin (PS network) was modified with amine, nitro, acetyl, and carboxyl groups. These materials were then applied in the on-line $\mu \mathrm{SPE}(5 \mathrm{mg}$ ) followed by LC-UV to determine a group of 22 analytes covering different polarities. The recovery results were again compared to commercial sorbents and revealed that XAD-COOH was better than all the other sorbents tested. XAD-COOH was also applied to analyze oil, hospital wastewater, and urine samples with successful results [12].

As for the copolymerization approach, this consists of copolymerizing a hydrophilic monomer (i.e., N-vinylpyrrolidone-NVP-, methacrylic acid-MAA-, 4-vinylpyridine-4VP-, etc.) with a crosslinking 
agent (DVB, ethyledimethacrylate-EDMA-, etc.). This strategy has been extensively applied to generate both commercial and in-house SPE sorbents. Although different hydrophilic polymeric materials are available, Oasis HLB (Waters), which is a copolymer of NVP-DVB with SSA of $800 \mathrm{~m}^{2} / \mathrm{g}$, has become the most popular due to its capacity and robustness as reported in many applications [2,5]. Oasis HLB was selected for a comparative study that included six sorbents with different SSAs and hydrophilicity features for determining a group of artificial sweeteners in water samples followed by LC-MS/MS. This selection was based on the better results achieved (recovery between 73-112\%) compared to the other materials tested [9]. This type of sorbent has been widely used in multi-residue analysis due to its generic features that are capable of retaining compounds with a broad range of properties. For instance, a multiresidue method to determine more than 1000 licit and illicit drugs from wastewater and surface water was developed based on SPE using the Oasis HLB, followed by LC with a quadrupole-time of flight (QToF) detector [34].

Despite the availability of commercial sorbents, various research groups have synthesized hydrophilic sorbents by means of copolymerization (Figure 1B). Our research group, for instance, prepared 4VP-DVB [35], N-vinylimidazole-divinylbenzene (NVIm-DVB) [14] that presented SSA of about $700 \mathrm{~m}^{2} / \mathrm{g}$. They were successfully applied to the SPE of different polar compounds, including phenolic compounds and pesticides from environmental water samples. Recently, the performance of different materials prepared from a combination of different monomers, such as MAA, 2-hydroxyethyl methacrylate (HEMA), EDMA, and DVB were compared. The material based on MAA-HEMA ultimately showed the best recoveries (from $75 \%$ to $100 \%$ ) for the extraction of a group of nerve agents from an organic matrix [15].

As mentioned earlier, another way of enhancing retention is by preparing HXL polymers obtained by post-crosslinking PS-DVB or vinylbenzyl chloride (VBC)-DVB precursors by means of a Friedel-Craft reaction. The HXL material obtained has a high micropore content and ultra-high SSA (up to $2000 \mathrm{~m}^{2} / \mathrm{g}$ ) [36]. In addition, a number of methods have been proposed for obtaining hydrophilic materials with HXL networks. For instance, a hydrophilic HXL terpolymer based on HEMA-VBC-DVB (25/25/50, mole ratio) with an SSA of $850 \mathrm{~m}^{2} / \mathrm{g}$ was synthesized [17]. This material was evaluated in the off-line SPE to extract a group of polar compounds from environmental water samples. The results showed that the presence of polar moieties together with the high SSA led to excellent recovery results $(>88 \%)$ that outperformed those achieved with commercially available sorbents. Table 1 provides some examples of HXL materials, both commercially available and in-house prepared.

\subsection{Selective Polymeric Materials}

Selective materials mainly comprise molecularly imprinted polymers (MIPs) and mixed-mode ion-exchange polymer materials when a washing step during the SPE protocol is applied. A common feature is their ability to retain target analytes through specific interactions after an effective washing step.

The selectivity of a MIP arises during synthesis, when functional monomers (which have the moieties to interact with the template) and crosslinker agents (to provide the suitable morphological properties) are polymerized in the presence of the target compound(s) (template) that controls the functionality of the cavities and size during polymerization. Once the polymerization is complete, the template is removed so that the target compound(s) can establish interactions with the shape, size, and functionalities of the binding sites generated. The preparation of MIPs and their application in SPE (so-called MISPE) have been extensively described and discussed in several reviews $[37,38]$ since they were first reported by Sellergren in 1994 [39]. Table 1 provides some selected examples of MIPs, covering in-house generated and commercially available.

In one example [19], different functional monomers and crosslinker agents were evaluated to prove the selectivity of the generated MIP toward caffeic acid and p-hydroxybenzoic acid for the selective extraction of polyphenols from olive oil wastewaters. From the monomers tested, it was found that 4VP and allylaniline showed better recognition than MMA and allylurea, and pentaerythritol triacrylate (PETRA) was more suitable as a crosslinker than EDMA due to its flexibility. Other studies 
compare the recognition ability of the MIP when different templates are tested. Several of the MIPs prepared using the same target compound as the template. However, template bleeding during SPE is one of the main drawbacks of MISPE. The "dummy" imprinting approach that involves the use of an analog molecule as the template can solve this problem. Phenolphthalein was successfully used as a dummy template for the selective MISPE extraction of bisphenol A from biological, environmental, and food samples [20].

Class selectivity can also occur when a MIP shows retention for the target compound and other structurally related compounds. For instance, a MIP prepared using ciprofloxacin as the template showed cross-reactivity for a group of fluoroquinolones, but not for other antibiotics [18]. Class selectivity can also be exploited by preparing multi-template MIPs, in which more than one template is used during the synthesis. Song et al. [22] developed a MIP using a group of 16 polycyclic aromatic hydrocarbons (PAHs) as the template. This multi-template MIP was then evaluated through the MISPE of PAHs from seawater, achieving even higher recoveries than the MIP prepared using a single PAH as a template.

Class selective MIPs have also been commercialized under different brands for different families of compounds such as nonsteroidal anti-inflammatory drugs (NSAIDs) (SupelMIP NSAIDs and Affilute MIP-NSAIDs), amphetamines (SupelMIP Amphetamine), and aminoglycosides (SupelMIP-Aminoglycosides). For instance, SupelMIP NSAIDs were evaluated through the selective determination of these pharmaceuticals in wastewater samples [23]. During the development of the method, a cleanup step was added to the MISPE protocol, so the matrix effect was lower than those obtained with Oasis HLB (non-selective sorbent). The recoveries achieved were similar for both sorbents.

The use of MIPs has become more widespread over recent years, and in addition to those prepared using polymeric frameworks, other supports such as metallic nanoparticles, hybrid materials, and carbon-based materials have also been developed. These types of MIPs are covered in the corresponding sections that follow.

Mixed-mode ion-exchange polymeric materials are an alternative for achieving selectivity and capacity in a single material for ionic or ionizable compounds as long as a washing step is included in the SPE protocol. These materials combine a polymeric skeleton (non-specific interactions) functionalized with ion-exchange groups (specific interactions with the charged analytes) and can be classified into four groups: strong cation exchangers (SCX), strong anion exchangers (SAX), weak cation exchangers (WCX) and weak anion exchangers (WAX). SCX sorbent is usually functionalized with sulfonic acid groups, whereas WCX is functionalized with a carboxylic acid. SAX sorbent usually has quaternary amine groups, while WAX has either ternary, secondary, or primary amines. These have progressively been applied in many different fields in recent years, and some reviews have also been published $[5,40]$. Due to their widespread use, several mixed-mode sorbents have been made commercially available, while some researchers have developed in-house versions. Table 1 presents some selected examples of mixed-mode ion-exchange polymeric materials and their applications.

SCX sorbents such as Oasis MCX, Strata-X-C, and Chromabond HR-X have been widely used for determining drugs of abuse and novel psychoactive substances in complex samples such as wastewater and biological fluids. This is because most of these drugs have basic properties and so they can interact ionically with the acidic groups of the SCX sorbent when these compounds are charged (at acidic $\mathrm{pH}$ values). With these conditions, an effective washing step based on the organic solvent can be applied, disrupting only the reversed-phase interactions and not the ionic interactions that caused the selectivity to arise. For instance, in the monitoring of cocaine and its main metabolites in wastewater and urine samples, Oasis MCX was selected from among other evaluated mixed-mode sorbents (Oasis MAX and Oasis WCX) and one generic sorbent (Oasis HLB), since it provided the best recoveries after a washing step consisting of $2 \mathrm{~mL}$ of $\mathrm{MeOH}$. The developed method based on SPE followed by LC-MS/MS provided recoveries higher than $60 \%$ and limits of quantification in the low $\mathrm{ng} / \mathrm{L}$ range [26]. Strata-X-WA and Oasis WAX were compared for the extraction of a group of perfluorinated carboxylic acids (PFCAs) from drinking, surface, and groundwater. Both provided good extraction recoveries for 
different compounds in the PCFA family, but Oasis WAX was ultimately selected for its robustness and quantitative recoveries [28].

An in-house HXL sorbent with WCX moieties (called HXLPP-WCX) was synthesized by copolymerization of the terpolymer based on MAA-VBC-DVB, which contains the carboxylic acid moieties in the MAA monomer. The HXLPP-WCX sorbent was successfully evaluated in the SPE and was used as a benchmark for the commercially available Oasis WCX and Strata-X WC during the extraction of a group of pharmaceuticals from environmental samples [31]. A copolymer based on 2-(diethylamino)ethyl methacrylate (DEAEMA) and DVB (DEAEMA-DVB) with a ternary amine was then functionalized with diglycidyl ether derivatives followed by quaternization with $\mathrm{N}, \mathrm{N}$-dimethylethanolamine (DMEA) to produce a mixed-mode SAX sorbent that was applied to extract pharmaceuticals from urine samples [32]. Glycidyl methacrylate (GMA)-DVB was functionalized with sulfonic groups to display SCX properties. This material was then successfully applied to extract alkylate-purine adducts from urine samples selectively [33].

\section{Inorganic-Based Materials}

Silica-based materials in bare form or modified with different functional groups, including $C_{18}, C_{8}$, phenyl, and amino have, for many years, been some of the most widely used in SPE and are still used today. However, other inorganic oxides and mixed inorganic polymers, as well as composites of them, have now emerged and been applied as SPE sorbents in order to improve the chemical and mechanical features of the originals. The following sections cover different types of inorganic-based materials, classified according to their preparation approach and interaction mechanisms. The organic-inorganic hybrid materials have been extensively evaluated as materials in different extraction techniques because of their features, especially the microextraction techniques such as solid-phase microextraction (SPME) and stir-bar sorptive extraction (SBSE), but also SPE in different formats such as pipette tip extraction and microextraction by packed syringe (MEPS) [41,42].

\subsection{Organic-Inorganic Hybrid Materials}

Organic-inorganic hybrid materials are prepared by mixing organic and inorganic materials into a single-phase system so that they interact with each other. The combination produces materials with unique features of enhanced thermal, mechanical, chemical, and other properties that lead to the improved sorption of compounds [43].

Sol-gel chemistry involves the hydrolysis and condensation of metal alkoxides in the presence of a catalyst and a solvent prior to forming the polymer network. Figure 2 shows the reactions involved during the sol-gel process. During the process, a liquid colloidal solution ("sol") evolves into a solid ("gel"). During condensation, the sol-gel active organic ligands are then progressively incorporated into the growing inorganic network. Different hybrid materials can be prepared by combining different sol-gel precursors and organic monomers, which makes sol-gel technology highly versatile. Tetraethoxysilane (TEOS) and tetramethoxysilane (TMOS) are the precursors most frequently used to generate inorganic polymers from silica-based materials. Table 2 shows some selected examples of the use of materials prepared using sol-gel technology for SPE. For example, a hybrid organic-inorganic sorbent containing methyltrimethoxysilane (MTMOS) combined with TEOS was prepared and applied as SPE sorbent for the extraction of a group of pesticides, achieving good results. These were attributed to the improved hydrophobicity, large SSA, and mesoporous structure of the material thanks to the introduction of the MTMOS-TEOS [44]. $\mathrm{SiO}_{2}$-based materials are usually used, although other common inorganic oxides such as titania or zirconia are also employed. For example, titania was used as a precursor in the sol-gel process to prepare ceramic composite nanofibers that were then evaluated as an SPE sorbent to extract naproxen and clobetasol from urine and plasma [45]. 
Table 2. Examples of the applications of inorganic-based materials in SPE.

\begin{tabular}{|c|c|c|c|c|c|c|}
\hline Type & Material & SPE Mode & Compounds & Sample & $\begin{array}{l}\text { Instrumental } \\
\text { Technique }\end{array}$ & Reference \\
\hline \multirow[t]{7}{*}{ Organic-inorganic hybrid } & sol-gel hybrid MTMOS-TEOS ${ }^{1}$ & off-line & organophosphorus & tap, mineral, river, fruit & GC-MS & [44] \\
\hline & sol-gel hybrid MTMOS-MPTMS ${ }^{2}$ & off-line & NSAIDs $^{3}$ & river & LC-UV & [46] \\
\hline & sol-gel composite $\mathrm{TiO}_{2}-\mathrm{Mn} / \mathrm{Fe} / \mathrm{Ni} / \mathrm{Co}$ & $\mu \mathrm{SPE}$ & pharmaceuticals & urine, plasma & LC-UV & [45] \\
\hline & $\mathrm{Si}-\beta-\mathrm{CD}^{4}$ & off-line & PAHs 5 & river, well, rainwater & LC-FL & [47] \\
\hline & $\mathrm{Si}-\beta-C D^{4}$ & off-line & methyl jasmonate & salty plant extract & LC-UV & [48] \\
\hline & $\mathrm{MIP} \mathrm{SiO}_{2}-\mathrm{TEOS}^{6}$ (oxindole) & on-line & paulatin & fruit, fruit juices & LC-UV & [49] \\
\hline & MIP TEOS-TEPS-3-APTMS 7 (sulfonamides) & off-line & sulfonamide antibiotic & milk & LC-DAD & [50] \\
\hline \multirow[t]{6}{*}{ Mesoporous silica } & MCM- $41^{8}$ & off-line & PAHs 5 & ambient air & GC-MS & [51] \\
\hline & SBA-15- $\mathrm{C}_{18}-\mathrm{CO}^{9}$ & off-line & $\mathrm{EDCs}^{10}$ & milk & LC-DAD & [52] \\
\hline & SBA-15- $\mathrm{NH}_{2}{ }^{9}$ & off-line & NSAIDs ${ }^{3}$ & tap, river, wastewater & LC-UV & [53] \\
\hline & MIP-SBA & off-line & bisphenol A & tap, well, wastewater & LC-UV & [54] \\
\hline & KIT-6 ${ }^{11}$ & off-line & pharmaceuticals & urine & LC-UV & [55] \\
\hline & UVM-Ti2 $5^{12}$ & off-line & organophosphorus & wastewater & GC-NPD $^{13}$ & [56] \\
\hline \multirow[t]{4}{*}{ LDHs } & $\mathrm{Mg}$-Al-LDH $\left(\mathrm{NO}_{3}{ }^{-}\right)$ & dispersive & aromatic acids & urine, sports drinks & LC-UV & [57] \\
\hline & $\mathrm{Ni}-\mathrm{Fe}-\mathrm{LDH}\left(\mathrm{NO}_{3}{ }^{-}\right)$ & dispersive & haloacetic acids & drinking water & LC-MS/MS & [58] \\
\hline & $\mathrm{Ni}-\mathrm{Fe}-\mathrm{LDH}\left(\mathrm{NO}_{3}^{-}\right)$ & $\mu \mathrm{MEPS}^{14}$ & NSAIDs $^{3}$ & urine & LC-UV & [59] \\
\hline & yarn@PPy@Cu-Cr-Fe LDH & in-tube & phenols & honey & LC-UV & [60] \\
\hline \multirow[t]{7}{*}{ MOF } & MIL-101 ${ }^{15}$ & dispersive $\mu \mathrm{SPE}$ & pantoprozole & plasma & LC-UV & [61] \\
\hline & MIL-68 ${ }^{15}$ & pipette tip & sulfonamides & lake, milk, meat & LC-UV & [62] \\
\hline & ZIF-8 ${ }^{16}$ & $\mu \mathrm{SPE}$ & $\mathrm{PAHs}^{5}$ & river & GC-MS & [63] \\
\hline & HKUST-1 17 & dispersive & herbicides & well water, soil, rice, tomato & IMS $^{18}$ & [64] \\
\hline & HKUST-1 17 & dispersive $\mu \mathrm{SPE}$ & parabens & $\begin{array}{l}\text { tap, swimming, spa water, } \\
\text { urine, cosmetic cream }\end{array}$ & LC-DAD & [65] \\
\hline & MOF-199 embedded NMA-EDMA 19 & off-line & ursolic acid & Chinese herbal medicine & LC-UV & [66] \\
\hline & $\mathrm{UiO}-66^{20}$ & dispersive $\mu \mathrm{SPE}$ & sialic acids & serum & LC-FL & [67] \\
\hline
\end{tabular}

${ }^{1}$ MTMOS-TEOS: methyltrimethoxysilane- tetraethyl orthosilicate; ${ }^{2}$ MPTMS: mercaptopropyltrimethoxysilane; ${ }^{3}$ NSAIDs: non-steroidal anti-inflammatory drugs; ${ }^{4} \beta$-CD: $\beta$-cyclodextrine;

${ }^{5}$ PAHs: polycyclic aromatic compounds; ${ }^{6}$ TEOS: tetraethyl orthosilicate; ${ }^{7}$ TEPS-3-APTMS: triethoxyphenylsilane-3-aminopropyltrimethoxysilane; ${ }^{8}$ MCM41: Mobile Composition of

Matter No. 41; ${ }^{9}$ SBA: Santa Barbara Amorphous; ${ }^{10}$ EDCs: endocrine disrupting compounds; ${ }^{11}$ KIT-6: KoreaAdvanced Institute of Science and Technology-6; ${ }^{12}$ UVM: Universidad

Valencia mesoporous; ${ }^{13}$ NPD: nitrogen-phosphorous detector; ${ }^{14}$ MEPS: microextraction by packed syringe; ${ }^{15}$ MIL: materials of Institute Lavoisier; ${ }^{16}$ ZIF: zeolite imidazole framework;

${ }^{17}$ HKUST: Hong Kong University of Science and Technology; ${ }^{18}$ IMS: ion mobility spectrometry; ${ }^{19}$ NMA-EDMA: N-methylolacrylamide-ethylenedimethacrylate; ${ }^{20}$ University of Oslo. 


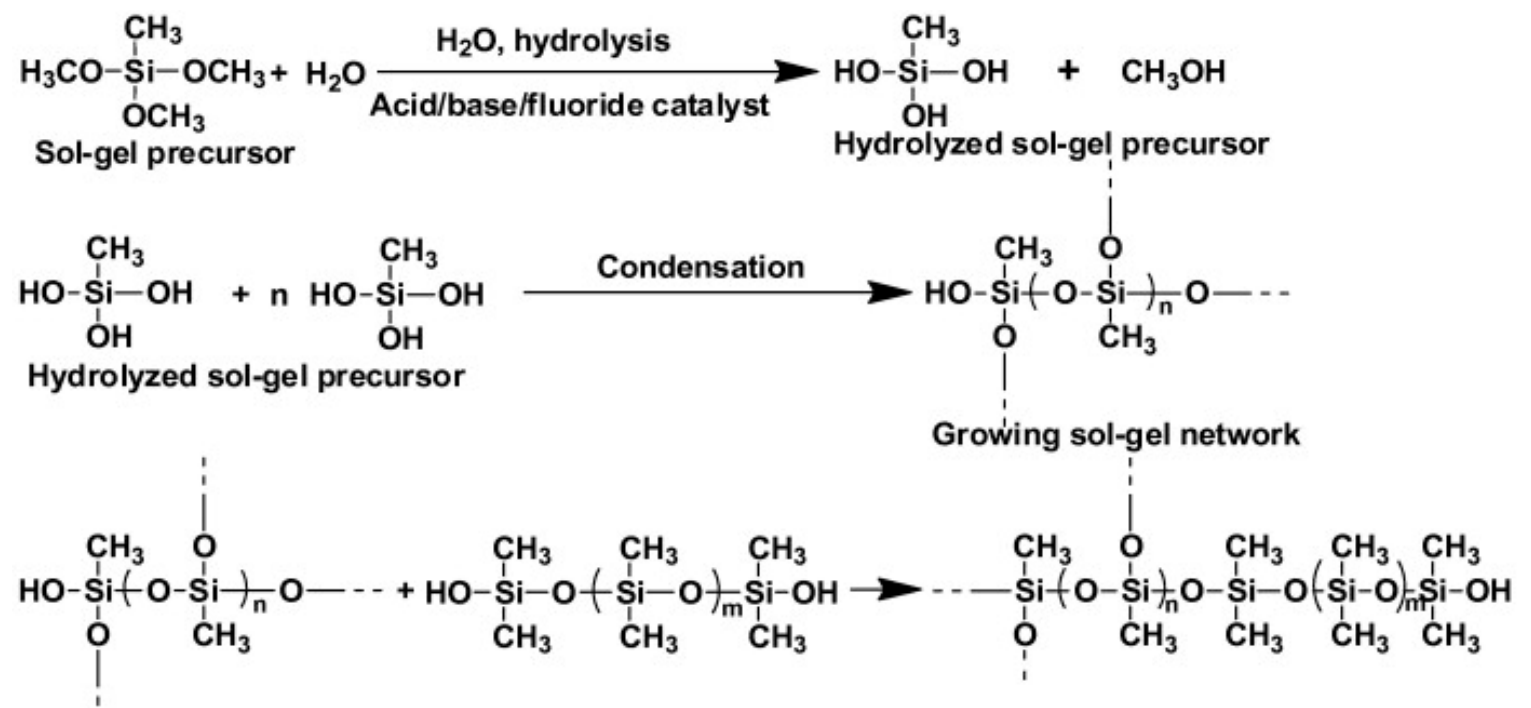

Growing sol-gel network Hydroxy-terminated PDMS Sol-gel network with integrated PDMS

Figure 2. Representation of the reactions involved during the synthesis of a sol-gel hybrid organic-inorganic polymeric network, reproduced from [68] with permission from Elsevier, 2013.

B-cyclodextrin materials that confer a certain degree of selectivity have been prepared using a similar sol-gel approach. For instance, Mauri-Acejo et al. [47] compared the efficiency of two materials, which either bound or included cyclodextrin on a microporous silica composite, for the retention of a group of PAHs. The authors found that with the bound approach, the losses of cyclodextrin were minimized, and thus, the sorbent's performance was better than the previous cyclodextrin-silica sorbents that had also been prepared as part of the strategy.

Different molecularly-imprinted hybrid organic-inorganic materials have been prepared using a sol-gel process but adding the template molecules to the reaction mixture. For example, a MIP for the selective extraction of patulin (mycotoxin) was prepared using a silica gel precursor and TEOS along with a dummy template (oxindole). The prepared MIP was successfully tested in the on-line SPE-LC-UV to determine this mycotoxin in fruit samples [49]. Recently a multi-template MIP for sulfonamide antibiotic was prepared using a sol-gel approach in which 3-aminopropyl trimethoxysilane (3-APTMS) and phenyl triethoxysilane (PTES), as well as the different sulfonamide templates, were used as sol-gel precursors, together with TEOS as a crosslinking agent during the sol-gel process [50]. It was then evaluated in the selective determination of sulfonamides from milk samples. The method achieved good results and was able to determine and identify these drugs in milk samples quantitatively.

\subsection{Mesoporous Silica Materials}

Highly ordered mesoporous silica are also explored as SPE sorbents due to their easy functionalization, high adsorption properties, and fast sorption kinetics [69]. Silica-based mesoporous materials are prepared using molecular precursors through the sol-gel process, which involves the use of a neutral or charged surfactant (to act as a template) in aqueous solution or water-soluble polymer. The polymerization and condensation of the silica precursors result in hexagonal mesoporous materials. After this, the template is removed by calcination. Depending on the disposition of the template (surfactant) during the synthesis, two different synthetic approaches can be distinguished: a "true liquid crystal templating procedure" and a "cooperative self-assembly process". Figure 3 shows the formation pathway of highly ordered mesoporous silica using the liquid crystal templating procedure. Regardless of the procedure, the properties of the mesoporous material can be tuned by modifying the synthetic parameters ( $\mathrm{pH}$ and temperature) and the type of surfactant and additive [3,69]. Since the first ordered mesoporous silica known as MCM41 (Mobile Composition of Matter No. 41) was prepared, different materials have been developed, including Santa Barbara amorphous (SBA), Fudan University 
(FDU) and hexagonal mesoporous silica (HMS). As an example, MCM41 was applied for the extraction of PAHs in ambient air, achieving similar results to those obtained using the polymeric-based sorbents XAD-2 and XAD-16 [51].

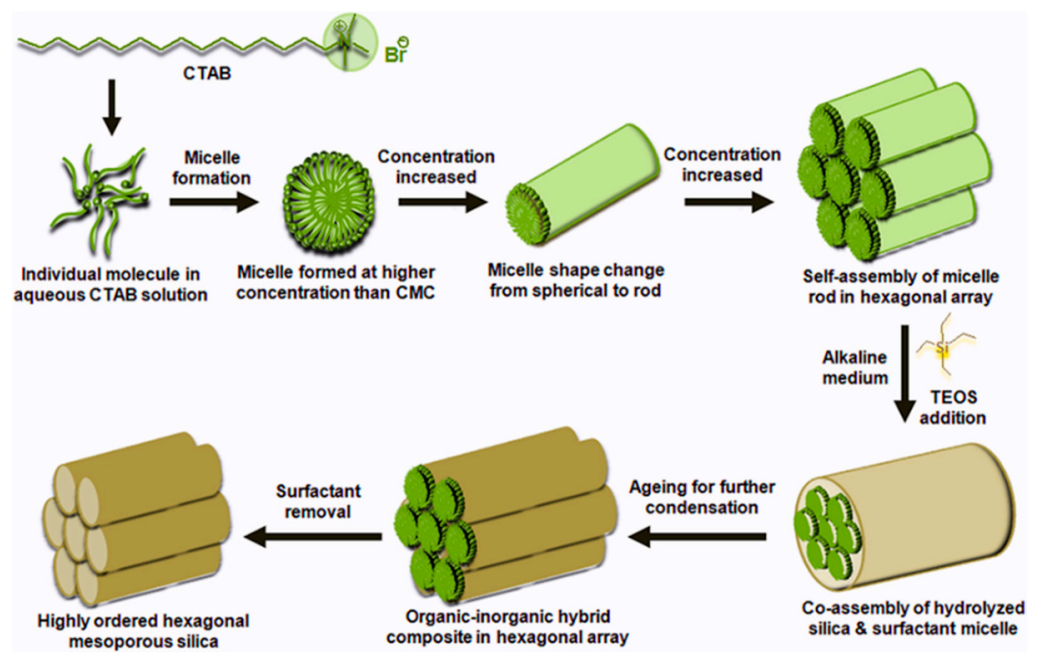

Figure 3. Schema of the formation of highly ordered mesoporous silica, reproduced from [70] with permission from Wiley, 2016.

In addition, the modification of the surface of the mesoporous silica further broadens the physical and chemical properties of these materials, expanding their applications. Table 2 shows some selected examples of the application of highly ordered mesoporous silica in SPE. For instance, a one-pot synthesized ordered mesoporous silica (SBA-15) functionalized with octadecyl groups (SBA-15-C $18-\mathrm{CO}$ ) was tested as an SPE sorbent in the determination of 12 endocrine-disrupting compounds (EDCs) in milk [52]. The novel sorbent enabled the extraction of most of the compounds with recoveries ranging from $72 \%$ to $105 \%$, results that are similar to those achieved with other extraction methods for the same compounds. SBA-15 was also functionalized with 3-[2-(2- aminoethylamino)ethylamino] propyl-trimethoxysilane (a silane with three amines) and then reacted with an excess of phenyl glycidyl ether to generate a mixed-mode anion-exchanger containing both anion-exchange (three amines) and reversed-phase (multiple ether-linked phenyls) functionalities in a single branched ligand [53]. This sorbent was successfully evaluated in the extraction of a group of acidic pharmaceuticals from environmental water samples, benefiting from both the reversed-phase and the SAX interactions between the sorbent and the analytes. Pellicer-Castell et al. [56] prepared different mesoporous silica sorbents (Universidad Valencia materials -UVM-), including pure, modified with cyclodextrins and doped with $\mathrm{Ti}$ and Fe (to tune the porosity of the original sorbent). Of these, a sorbent doped with $\mathrm{Ti}$ (UVM7-Ti25) presented the best porous properties, and thus, provided the best results for the extraction of a group of organophosphorus compounds from environmental water samples. Mesoporous silica have also been modified with dendrimers (macromolecules with highly repetitive branched structures) to obtain materials, combining the advantages of dendrimers (great functionalization) with the ease of separation of the solid support. Li et al. [55] adopted this strategy to prepare a sorbent for SPE that combined reversed-phase with anion-exchange interactions. This material was then applied to the extraction of a group of acidic drugs from urine and achieved good results that were attributed to the specific (anionic) interactions between the sorbent and the target analytes.

\subsection{Layered Double Hydroxides}

Layered double hydroxides (LDHs) are nanomaterials structured in a 2D form that consist of positively-charged layers of metal hydroxides separated by an interlayer region containing anions and some water molecules between layers [71,72]. Figure 4 shows a schematic overview 
of LDHs. They usually contain both divalent and trivalent metal cations following the formula $\left[\mathrm{M}^{2+}{ }_{1-\mathrm{x}} \mathrm{M}^{3+}{ }_{\mathrm{x}}(\mathrm{OH})_{2}\right]\left[\mathrm{A}^{\mathrm{n}-}\right]_{\mathrm{x} / \mathrm{n}} \cdot \mathrm{zH}_{2} \mathrm{O}$, where $\mathrm{M}^{2+}$ may be cations such as $\mathrm{Mg}^{2+}, \mathrm{Zn}^{2+}$, and $\mathrm{Ni}^{2+}, \mathrm{M}^{3+}$ may be cations such as $\mathrm{Al}^{3+}, \mathrm{Ga}^{3+}, \mathrm{Fe}^{3+}$ and $\mathrm{Mn}^{3+}, \mathrm{An}^{-}$may be anions such as $\mathrm{CO}_{3}{ }^{2-}, \mathrm{NO}_{3}{ }^{-}, \mathrm{Cl}^{-}, \mathrm{SO}_{4}{ }^{2-}$ and $\mathrm{RCO}^{2-}$, and $\mathrm{x}$ is the mole fraction of $\mathrm{M}^{3+}$. $\mathrm{LDH}$ features include a large SSA, diversity of chemical composition, anion exchange capabilities, and a water-resistant structure that makes them suitable SPE sorbents. It should be borne in mind that LDHs can provide different interaction mechanisms such as anion-exchange interactions, which means that the selectivity in complex samples can be further exploited. Furthermore, as LDHs are unstable at acidic $\mathrm{pH}$, an interesting feature is that they can be dissolved in this acidic medium so that, once the extraction step has been carried out using LDH materials, the addition of acidic media dissolves the sorbent without any need for an elution step (which could be incomplete). Doing this means that the speed and efficiency of the overall SPE procedure are enhanced [57]. It should also be noted that because of this dissolvable feature, dispersive SPE (dSPE) is the most usual mode of extraction. This practice, using dissolvable LDHs, has been further exploited in various studies [71,73]. Table 2 shows some selected examples of the application of LDHs in SPE. For instance, dissolvable $\mathrm{Mg}-\mathrm{Al} \mathrm{LDH}$ (using $\mathrm{NO}_{3}{ }^{-}, \mathrm{Cl}^{-}$and $\mathrm{CO}_{3}{ }^{2-}$ as anions) were applied in dSPE to extract a group of aromatic acids from urine and sports drink samples [57] and haloacetic acids from drinking water [58]. In another example, Ni-Fe LDH-based sorbent using $\mathrm{Ni}\left(\mathrm{NO}_{3}\right)_{2}$ and Fe( $\left.\mathrm{NO}_{3}\right)_{3}$, was prepared, followed by urea hydrolysis using coprecipitation [59]. It was then applied in the $\mu$ SPE by packed sorbent in which $8 \mathrm{mg}$ of particles was inserted in a spinal syringe connected to a syringe pump. Using an optimized SPE protocol, the target analytes (NSAIDs) were successfully extracted, yielding recoveries within the range 53-92\%. The method was then applied to extract NSAIDs from different urine samples with results outperforming those already reported using other extraction materials [59].

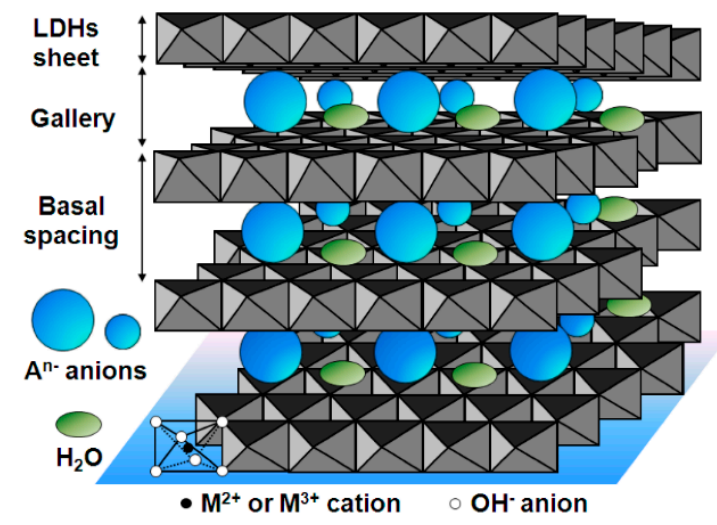

Figure 4. Schema of the representation of layered double hydroxides (LDHs), reproduced from [72] with permission from MDPI, 2014.

\subsection{Metal-Organic Frameworks}

Metal-organic frameworks (MOFs) are porous coordination polymers consisting of transition metal clusters and organic ligands that create 3D organic-inorganic hybrid networks [71,74]. There are different types of MOF-a schema of which is shown in Figure 5-that include a zeolite imidazole framework (ZIF) (Figure 5A), metal atoms linked with imidazolate and functionalized imidazolate ligands through a nitrogen atom, materials of Institut Lavoisier (MILs) (Figure 5B) based on trivalent metal centers and carboxylic acid bridging ligands, materials of University of Oslo (UiO) (Figure 5C) that consist of a building block based on zirconium, and materials of Hong Kong University of Science and Technology (HKUST) (Figure 5D), which is a 3D structure based on copper. Although they have different properties, in general terms, they all share high porosity as a result of their nanoscale cavities and high SSA, plus good thermal and chemical stability. These properties make MOFs excellent candidates for various applications in the area of sample preparation. However, as the direct use of MOFs as nano/microcrystals presents a number of limitations when packing in an SPE cartridge or in 
dSPE (since this involves centrifugation and filtration) due to their small particle size and nonspherical shape, they should be combined with different supports in order to be readily applied as SPE materials. These strategies have also been extensively used to prepare materials for other sorptive extraction techniques, such as SPME and membrane-based techniques $[3,71,74]$. Table 2 lists some examples of the use of MOFs in SPE, as well as those combined with different supports for the same use.

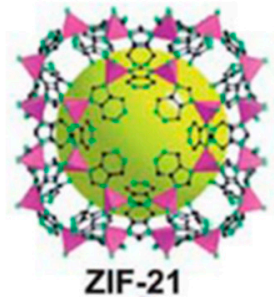

A

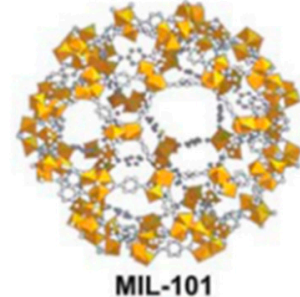

B

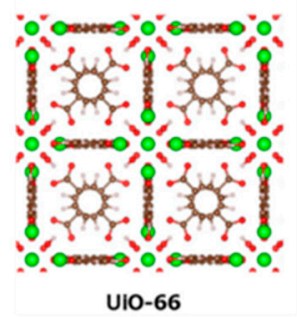

C

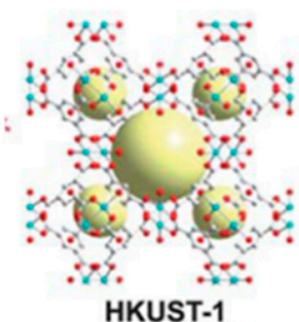

D

Figure 5. Representative examples of metal-organic framework (MOFs). ZIF-21 (A), MIL-101 (B), and HKUST-1 (D) reproduced from [75] with permission from The Royal Society of Chemistry, 2010; and UIO-66 (C), reproduced from [76] with permission from Elsevier, 2016.

MOFs are generally applied in dSPE mode [61,64,65,67]. For example, HUSKT-1 (based on a copper-benzene-1,3,5-tricarboxylate framework) was used as sorbent in dSPE combined with ion mobility spectrometry (IMS) for the preconcentration of herbicide from water, soil, and agricultural-product samples. The sorbent showed high stability and reusability and high recoveries (94-108\%) with a preconcentration factor of 20 [64]. MOFs embedded in polymeric monoliths is another strategy, which has mainly been used in SPME and other extraction techniques, but also SPE. For instance, a monolithic column based on N-methyloacrylamide (NMA) and EDMA were used as the host material for embedding MOF-199 (copper-1,3,5-benzenetricaboxylate). By incorporating the MOF particles, the SSA and permeability of the monolith improved significantly. It was then applied in on-line SPE-LC-UV to determine ursolic acid from Chinese herbal medicine with successful results in terms of recovery, reproducibility, and accuracy [66]. Other approaches have been based on incorporating the MOFs into beads, which in most cases, are magnetic. One such case was the incorporation of MIL-100(Fe) into $\mathrm{Fe}_{3} \mathrm{O}_{4}$ nanoparticles for application in magnetic SPE [77]. In a more sophisticated stage, Maya et al. [78] prepared MOF in the form of core-shell particles through the immobilization of precursor metal oxides followed by their in situ conversion into MOF by reaction with the appropriate organic linker. In this case [78], in the first instance, a layer of $\mathrm{ZnO}$ is coated onto cation exchange PS beads to obtain ZnO@PS precursor beads, which are then reacted with an organic linker (2-methylimidazole) to obtain ZIF-8@ZnO@PS. The authors compared the performance of these beads in the extraction of a group of EDCs from water samples with that achieved with the beads obtained when ZIF-8 was directly immobilized in the polymer beads. They found that the extraction performance was much lower than that obtained with the in situ conversion approach.

MOFs have also been used as precursors or as part of other sorptive materials, such as metallic nanoparticles and porous magnetic carbons. These are covered in the following sections of this review.

\subsection{Metallic Nanoparticles}

Metallic nanoparticles (NPs), including $\mathrm{Fe}_{3} \mathrm{O}_{4}, \mathrm{TiO}_{2}, \mathrm{ZrO}_{2}, \mathrm{Al}_{2} \mathrm{O}_{3}$, among others, in bare form or modified with different functional coatings, are particularly characterized by their large SSA, which gives rise to high sorption capacity. There are also magnetic NPs (MNPs) that mainly contain iron, nickel, and cobalt and their oxides, with magnetite $\left(\mathrm{Fe}_{3} \mathrm{O}_{4}\right)$ and maghemite $\left(\gamma-\mathrm{Fe}_{2} \mathrm{O}_{3}\right)$ being the most popular. MNPs are especially useful because of the strong magnetic properties that make NPs easy to isolate using an external magnetic field without the need for centrifugation and filtration [73,79]. 
These features make MNPs very straightforward for use in dSPE, also known as magnetic SPE (MSPE), making them the main SPE mode used. Table 3 lists some selected examples where MNPs are used in dSPE.

Different types of coating have been applied to the surface of NPs and MNPs, including polymer-based, silica-based, MOFs, multiwalled carbon nanotubes (MWCNTs), and graphene (G) or graphene oxide (GO). One of the most frequently used is coated with silica $\left(\mathrm{Fe}_{3} \mathrm{O}_{4} @ \mathrm{SiO}_{2}\right)$ and functionalized with different moieties, such as the $\mathrm{C}_{18}$ groups $\left(\mathrm{Fe}_{3} \mathrm{O}_{4} @ \mathrm{SiO}_{2}-\mathrm{C}_{18}\right)[79,80]$. MNPs are covered in different sections of this review, and examples of their applications can be found in Table 3. In the present section, we focus on the preparation and application of $\mathrm{Fe}_{3} \mathrm{O}_{4} @ \mathrm{SiO}_{2}-\mathrm{C}_{18}$ as an example of one of the most popular MNPs. Figure $6 \mathrm{~A}$ shows the schematic procedure for obtaining $\mathrm{Fe}_{3} \mathrm{O}_{4} @ \mathrm{SiO}_{2}-\mathrm{C}_{18}$. This comprises three steps: (1) the magnetite was prepared from ferric chloride, (2) the $\mathrm{Fe}_{3} \mathrm{O}_{4}$ NPs obtained were then treated with TEOS to start the sol-gel process, and (3) finally, the $\mathrm{Fe}_{3} \mathrm{O}_{4} @ \mathrm{SiO}_{2} \mathrm{NPs}$ were reacted with chlorodimethyl-n-octadecylsilane to obtain the $\mathrm{Fe}_{3} \mathrm{O}_{4} @ \mathrm{SiO}_{2}-\mathrm{C}_{18}$. In the case studied here [81], these MNPs based on $\mathrm{Fe}_{3} \mathrm{O}_{4} @ \mathrm{SiO}_{2}-\mathrm{C}_{18}$ were applied to the extraction of a corticosteroid from rat plasma using the MSPE mode, achieving high recoveries thanks to the contribution of the hydrophobic part $\left(\mathrm{C}_{18}\right.$ chains) that strongly interacts with the target compound.

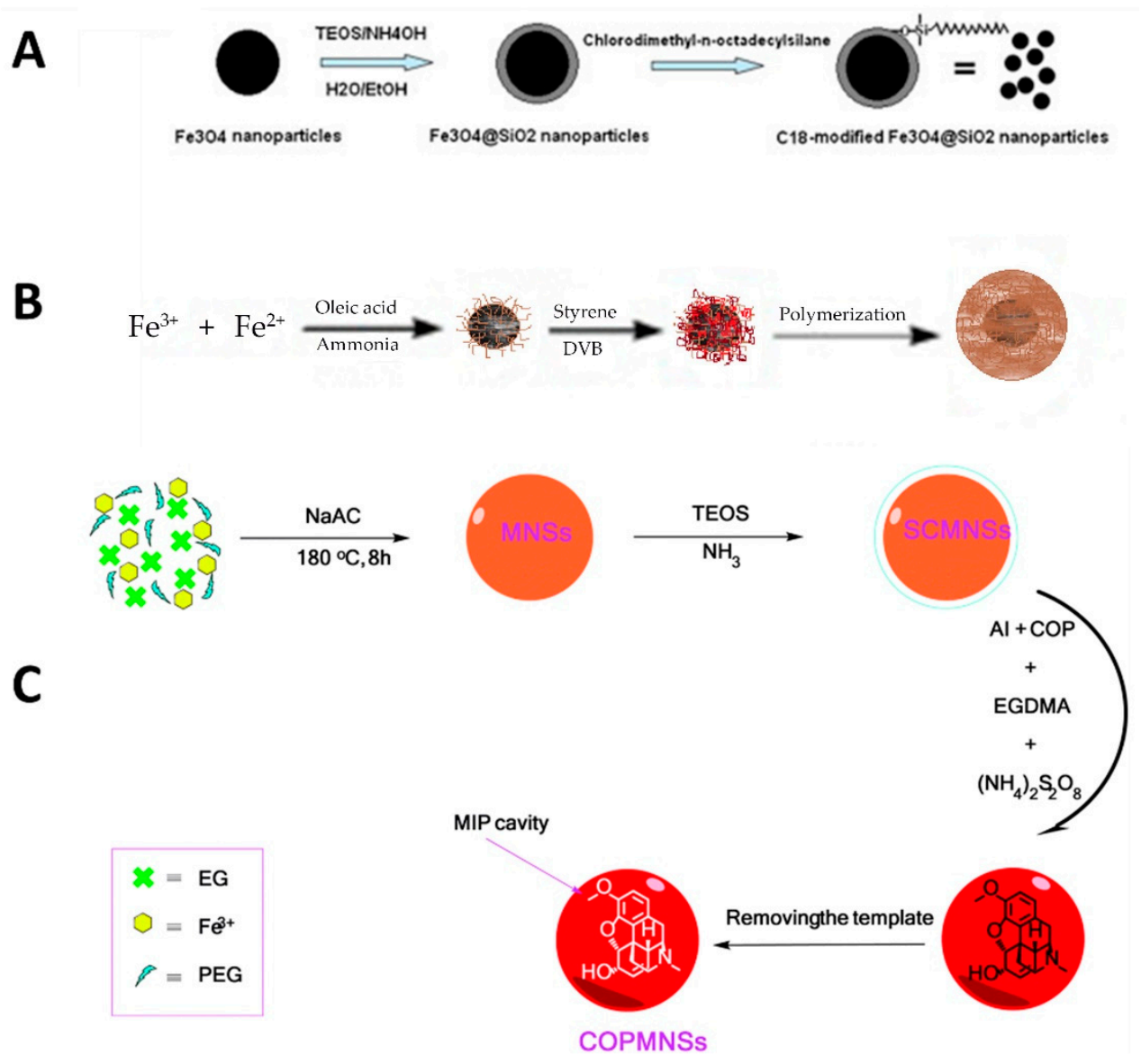

Figure 6. Schema of the synthetic procedure for obtaining (A) $\mathrm{Fe}_{3} \mathrm{O}_{4} @ \mathrm{SiO}_{2}-\mathrm{C}_{18},(\mathbf{B}) \mathrm{Fe}_{3} \mathrm{O}_{4} @ P S-D V B$, and (C) $\mathrm{Fe}_{3} \mathrm{O}_{4} @ \mathrm{SiO}_{2}$-polymer-MIP. Reproduced from [81] and [82] with permission from Elsevier, 2010 and 2012, respectively; and from [85] with permission from The Royal Society of Chemistry, 2016. 
Table 3. Examples of the applications of metallic nanoparticle materials in SPE.

\begin{tabular}{|c|c|c|c|c|c|c|}
\hline Type & Material & SPE Mode & Compounds & Sample & $\begin{array}{l}\text { Instrumental } \\
\text { Technique }\end{array}$ & Reference \\
\hline \multirow[t]{3}{*}{ Silica-based } & $\mathrm{Fe}_{3} \mathrm{O}_{4} @ \mathrm{SiO}_{2}-\mathrm{C}_{18}$ & magnetic & corticosteroid & plasma & LC-UV & [81] \\
\hline & $\mathrm{Fe}_{3} \mathrm{O}_{4} @ \mathrm{SiO}_{2}-\mathrm{C}_{18}$ & magnetic & pesticides & pond water & GC-MS & [86] \\
\hline & $\mathrm{Fe}_{3} \mathrm{O}_{4} @ \mathrm{SiO}_{2}-\mathrm{MIP}$ & magnetic & codeine & urine & LC-UV & [85] \\
\hline LDH & Fe@Mg-Al-LDH & magnetic & bisphenol A, nonylphenol & river, wastewater & LC-UV & [87] \\
\hline \multirow[t]{2}{*}{$\mathrm{MOF}$} & $\mathrm{Fe}_{3} \mathrm{O}_{4} @ \mathrm{MIL}-100$ & magnetic $\mu \mathrm{SPE}$ & PAHs $^{1}$ & tap, well, pond water & LC-FD & [77] \\
\hline & $\mathrm{Fe}_{3} \mathrm{O}_{4} @ \mathrm{ZIF}-8$ & magnetic & $\mathrm{EDC}^{2}$ & drinking water & LC-UV & [78] \\
\hline \multirow[t]{3}{*}{ Polymer-based } & $\mathrm{Fe}_{3} \mathrm{O}_{4} @ P S-D V B$ & magnetic & fenitrothion & water, urine & UV & [82] \\
\hline & $\mathrm{Fe}_{3} \mathrm{O}_{4} @$ polyaniline & magnetic $\mu \mathrm{SPE}$ & benzodiazepines & $\begin{array}{l}\text { tap, river, well, lake water, } \\
\text { plasma, urine }\end{array}$ & LC-UV & [83] \\
\hline & $\mathrm{Fe}_{3} \mathrm{O}_{4} @$ polypyrrole & magnetic $\mu \mathrm{SPE}$ & antidepressant drugs & plasma, urine & LC-UV & [84] \\
\hline \multirow[t]{5}{*}{ Carbon-based } & $\mathrm{Fe}_{3} \mathrm{O}_{4} @ \mathrm{C}_{60}$ fullerenes & magnetic & azodyes & wastewater & CE-UV & [88] \\
\hline & $\mathrm{Fe}_{3} \mathrm{O}_{4} @ \mathrm{MWCNTs}^{3}$ & magnetic & aconitites & serum & LC-DAD & [89] \\
\hline & $\mathrm{Fe}_{3} \mathrm{O}_{4} @ \mathrm{GO}^{4}$ & magnetic & PAHs ${ }^{1}$ & urine & LC-MS & [90] \\
\hline & $\mathrm{Fe}_{3} \mathrm{O}_{4} @ \mathrm{SiO}_{2} @ \mathrm{GO} @ \mathrm{IL}^{5}$ & magnetic & chlorophenols & tap water & LC-MS/MS & [91] \\
\hline & $\mathrm{Fe}_{3} \mathrm{O}_{4} @ \mathrm{GO} @$ hemimicelles & magnetic & PFAS $^{6}$ & river, wastewater & LC-MS/MS & [92] \\
\hline
\end{tabular}

perfluoroalkyl substances. 
Other authors have included the polymeric shell in the magnetite core so as to obtain polymeric MNPs. Figure 6B shows a schema of the synthetic procedure used to obtain $\mathrm{Fe}_{3} \mathrm{O}_{4} @ P S-D V B$ MNPs. Essentially, once the magnetite was prepared, it was mixed with the monomer mixture to polymerize under the polymerization conditions [82]. This procedure is easy to achieve, but the authors found that these $\mathrm{Fe}_{3} \mathrm{O}_{4} @$ PS-DVB MNPs showed weak magnetic properties during the MSPE procedure. This was solved by adding bare MNPs to the extraction mixture to provide faster and more efficient precipitation of the polymeric MNPs from the extraction mixture. After this, the performance of the $\mathrm{Fe}_{3} \mathrm{O}_{4} @ P S-D V B$ MNPs to extract a group of pesticides from different types of the sample was successfully achieved [82]. Other polymeric coatings have also been prepared in MNP, using polyaniline [83] and pyrrolidone, for example [84]. MIPs have also been prepared using magnetite as the core in order for the MNPs generated to have selectivity when applied in MSPE procedures. For instance, a MIP MNPs was developed for the selective extraction of codeine from urine [85]. In this case, magnetite was first coated with silica; then these $\mathrm{Fe}_{3} \mathrm{O}_{4} @ \mathrm{SiO}_{2} \mathrm{MNPs}$ were reacted with the functional monomer, the crosslinking agent and the template in order to generate cavities in shape and form, able to interact with the target compound specifically. Figure $6 \mathrm{C}$ shows the schema of this synthetic procedure.

\section{Carbon-Based Materials}

Carbon exists in various allotropic forms ranging from the classical GCBs and PGCs to fullerenes, carbon nanotubes (CNTs), carbon nanofibers, carbon nanodisks, G, and GO, among others. However, fullerenes, CNTs, G and GO are mainly used for other analytical applications rather than SPE. Figure 7 presents their structures, and Table 4 summarizes their most relevant applications as sorbents for SPE. They have been explored as SPE materials due to their features of chemical and thermal stability, ordered porosity, and high SSA, which promote high sorption capacity towards the analytes [93]. The development of new carbon-based materials for sample preparation has recently been reported. These use the carbonization of low-cost commercially available polymers or biomass to reduce production costs that have been also reported [71]. For example, biomass-derived hierarchically porous carbon was prepared by hydrothermal treatment and the carbonization of banana peel. It was then applied as SPE sorbent for the extraction of carbamate pesticides from watermelon and cucumber with good results thanks to the respectable SSA (ca. $500 \mathrm{~m}^{2} / \mathrm{g}$ ) that promoted interactions with the target compounds [94].

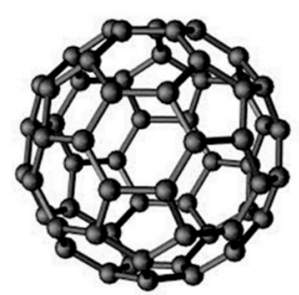

A) Fullerene

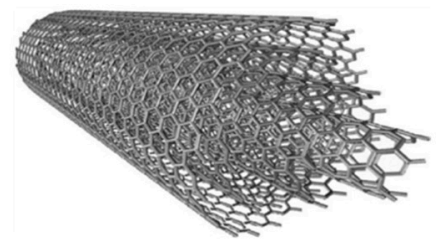

B) MWCNTS

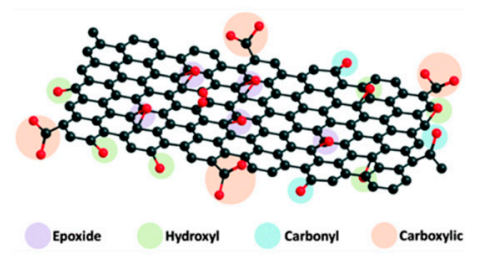

C) $\mathrm{GO}$

Figure 7. Examples of carbon nanomaterials used in SPE. Fullerene, (A); multi wallet carbon nanotubes (MWCNTs), (B); graphene oxide (GO), (C).

\subsection{Fullerenes}

Fullerenes are polyhedral nanostructures made up of 5-6 membered carbon rings in the form of a hollow sphere, tube, or ellipsoid (Figure 7A). Due to their extreme insolubility in aqueous or organic media, their use is very limited. However, their lower aggregation predisposition simplifies their application in SPE. In one of the earliest studies [95] on $\mathrm{C}_{60}$ fullerenes, their SPE performance was compared to that of Tenax TA and $\mathrm{C}_{18}$ sorbents for the extraction of BTEX compounds from the sea and wastewater samples. The results for $\mathrm{C}_{60}$ fullerenes revealed that they were better in terms of the preconcentration factor achieved as well as for their precision and reusability. $\mathrm{Fe}_{3} \mathrm{O}_{4}$-activated 
carbon, $\mathrm{Fe}_{3} \mathrm{O}_{4}$-fullerene, and $\mathrm{Fe}_{3} \mathrm{O}_{4}$-activated carbon-fullerene nanomaterials were prepared for the extraction of a group of azo dyes from wastewater samples [88]. In this comparison, $5 \mathrm{mg}$ of each material was dispersed in the sample to conduct dSPE under optimized conditions. The best recoveries were achieved by the mixed material $\left(\mathrm{Fe}_{3} \mathrm{O}_{4}\right.$-activated carbon-fullerene) since it provided more diverse interactions ( $\pi-\pi$, hydrophobic) and spatial distribution with the analytes compared to the individual forms.

\subsection{Carbon Nanotubes}

CNTs are formed by rolling graphene sheets into a cylindrical shape. Single-walled CNTs (SWCNTs) are based on one sheet, whereas those with more than one sheet are known as MWCNTs (Figure 7B). Their main properties as sorbents are their high SSA that enables $\pi-\pi$ interactions, and the easy functionalization of their surface chemistry with different functional groups [93]. The performance of MWCNT sorbent was compared to that of $\mathrm{C}_{18}$ silica and activated carbon for the SPE of a group of pesticides from different surface water samples [96]. The results indicated that the MWCNT showed better enrichment performance. Specifically, apart from its high SSA, the sorbent interacts strongly with the benzene rings of carbamates thanks to the surface of the MWCNT being made up of hexagonal arrays of carbon atoms in graphene sheets. MWCNT composites and their surface modification have also been explored via chemical treatment with various reagents. The purpose of this is to improve their adsorption properties and extraction efficiency further. Lalovic et al. [97] compared the performance of bare MWCNTs and those modified with acidic or basic reagents (i.e., $\mathrm{HCl}, \mathrm{HNO}_{3}$, and $\mathrm{NaOH}$ ) for the extraction of multi-class pharmaceuticals from environmental water. It was found that treatment with $\mathrm{HCl}$ decreases the content of oxygen groups on the surface and thus reduces the number of electron-acceptor groups, which favors extraction efficiency towards the target compounds.

\subsection{Graphene and Graphene Oxide}

G's structure is a thin honeycomb lattice of carbon atoms, while GO has the same structure but containing multi-functional groups such as carboxyl, hydroxyl, and epoxides (Figure 7C), which can be further reduced to convert into reduced GO (rGO). These materials exhibit high SSA ( $>2000 \mathrm{~m}^{2} / \mathrm{g}$ ), high mechanical strength, and thermal conductivity, and in addition, GO exhibits high polarizability. In spite of these properties, the application of $\mathrm{G}$ as a sorbent is limited due to its lower water dispersibility. GO overcomes this limitation and is more frequently used in sample preparation. For instance, GO was applied as material in the SPE combined with electromembrane extraction (EME) followed by capillary electrophoresis (CE) for the determination of chlorphen oxyacid herbicides in environmental water samples [98]. In a further step, the GO framework (GOF) consisting of layers of GO interconnected by linkers such as boric acid was developed. Li et al. [99] synthesized GOF using 1,4-phenyldiboronic acid as the linker, which was then successfully evaluated as material in SPE for the extraction of phenylurea herbicides in celery and lake water samples.

In addition, the synthesis of hybrid materials produced by G- or GO-bound silica (i.e., G@silica) or composite materials produced by combining with different inorganic and organic materials have been also proposed $[79,100]$. For instance, $\mathrm{GO}$ grafted with $\mathrm{SiO}_{2}\left(\mathrm{GO} @ \mathrm{SiO}_{2}\right)$ was used in dSPE for the extraction of phenolic acid from urine. Excellent recoveries (up to 95\%) were achieved with a small mass of material $(20 \mathrm{mg})$ [101]. A composite of $\mathrm{Fe}_{3} \mathrm{O}_{4} @ \mathrm{SiO}_{2} @ \mathrm{GO}$ was further modified with ionic liquid (IL) and successfully applied in the preconcentration of a group of polar and non-polar chlorophenols from the tap, well, and river water prior to their determination by LC-MS/MS [91]. 
Table 4. Examples of the applications of carbon-based materials in SPE.

\begin{tabular}{|c|c|c|c|c|c|c|}
\hline Type & Material & SPE Mode & Compounds & Sample & $\begin{array}{l}\text { Instrumental } \\
\text { Technique }\end{array}$ & Reference \\
\hline Fullerenes & $\begin{array}{c}\mathrm{C}_{60} \\
\mathrm{SiO}_{2}-\mathrm{C}_{60}\end{array}$ & $\begin{array}{c}\text { on-line } \\
\text { dispersive }\end{array}$ & $\begin{array}{l}\text { BTEX }^{1} \\
\text { peptides }\end{array}$ & $\begin{array}{l}\text { sea, wastewater } \\
\text { serum }\end{array}$ & $\begin{array}{c}\text { GC-MS } \\
\text { MALDI-TOF-MS } 2\end{array}$ & $\begin{array}{c}{[95]} \\
{[102]}\end{array}$ \\
\hline \multirow[t]{4}{*}{$\begin{array}{c}\text { Carbon } \\
\text { nanotubes }\end{array}$} & SWCNTs $^{3}$ & SPE & salicylic acid & river & CE-UV & [103] \\
\hline & MWCNTs ${ }^{4}$ & SPE & $\begin{array}{l}\text { carbamate } \\
\text { pesticides }\end{array}$ & tap, river water & LC-MS & [96] \\
\hline & $\mathrm{SiO}_{2}-\mathrm{MWCNTs}$ & SPE & $\begin{array}{l}\text { nucleosides, } \\
\text { nucleobases }\end{array}$ & urine & LC-DAD & [104] \\
\hline & $\mathrm{MWCNTs}^{4}-\mathrm{HCl}$ & dispersive & pharmaceuticals & $\begin{array}{l}\text { surface, } \\
\text { groundwater }\end{array}$ & LC-MS/MS & [97] \\
\hline \multirow[t]{3}{*}{ Graphene } & $\mathrm{G}^{5}$ & dispersive & $\begin{array}{l}\text { carbamate } \\
\text { pesticides }\end{array}$ & fruit juice & LC-MS/MS & [105] \\
\hline & $\begin{array}{c}\mathrm{GO}^{6} \\
\mathrm{SiO}_{2}-\mathrm{GO}\end{array}$ & $\begin{array}{c}\text { SPE } \\
\text { dispersive }\end{array}$ & $\begin{array}{l}\text { herbicides } \\
\text { phenolic acids }\end{array}$ & $\begin{array}{c}\text { river, seawater } \\
\text { urine }\end{array}$ & $\begin{array}{l}\text { CE-UV } \\
\text { LC-UV }\end{array}$ & $\begin{array}{c}{[98]} \\
{[101]}\end{array}$ \\
\hline & GO-1,4-PDBA $^{7}$ & SPE & herbicides & $\begin{array}{l}\text { pond water, } \\
\text { celery }\end{array}$ & LC-DAD & [99] \\
\hline
\end{tabular}

${ }^{1}$ BTEX: benzene, toluene, ethylbenzene, and xylene; ${ }^{2}$ MALDI-TOF: matrix-assisted laser desorption-time-of-flight;

${ }^{3}$ SWCNTs: single-walled carbon nanotubes; ${ }^{4}$ MWCNTs: multiwalled carbon nanotubes; ${ }^{5}$ G: graphene; ${ }^{6}$ GO: graphene oxide; ${ }^{7}$ 1,4-PDBA: 1,4-phenyldiboric acid.

\section{Other Materials}

\subsection{Silicates}

Minerals such as clays have been proposed as materials for sample preparation due to their low cost. However, their characteristic shape and size make them more suitable for use as a support or in disperse mode rather than to be used directly in SPE. Montmorillonite (MMT), a layered silicate that has been used as a strengthening material for polymers due to its high SSA, was applied as support to prepare magnetic particles coated with $\mathrm{C}_{16}$-silica using the sol-gel approach [106]. Fifty $\mathrm{mg}$ of material was then applied in dSPE to extract bisphenol A from a $50 \mathrm{~mL}$ water sample from environmentally different origins such as leachate, river, and well water, achieving complete recoveries (95-98\%) and enrichment factors greater than 30 .

Zeolites are another type of silicate that present similar properties and limitations as clays. Their main application in sample preparation is as a support or in dispersed mode. For instance, zeolite $\mathrm{NaY}$ modified with polyaniline through in-situ oxidative polymerization was prepared to be applied for the preconcentration of multi-class pesticides using dSPE in environmental and fruit samples, with recoveries of the target compounds ranging between 64-128\% [107]. Zeolite in the form of networks is a subclass of MOF (see Section 3.4), and other zeolites used in sorptive extraction techniques can be found in specific reviews [71,108].

\subsection{Natural Sorbents}

Cotton wool $(500 \mu \mathrm{g})$ was inserted into SPE micro tips for the purification of glycan and glycopeptides from biological samples for subsequent mass spectrometric detection. The results revealed the removal of salts and nonglycosylated peptides, among other things, leading to the successful determination of the target compounds [109]. Pollen with a high hydroxyl content and chemically stable was also explored as an SPE sorbent in the enrichment of plant growth regulators in fruits and vegetables [110]. Its morphological properties (SSA $30 \mathrm{~m}^{2} / \mathrm{g}$ and $30-40 \mu \mathrm{m}$ particle size) and suitable chemical properties (presence of hydroxyl moieties) made this natural material suitable for the extraction and purification of the target compounds. Cigarette filters were also used as a sorbent to solid-phase extract a group of organophosphorus and organochlorine pesticides from environmental samples before gas chromatography with mass spectrometry (GC-MS) analysis. For the performance, $120 \mathrm{mg}$ of cigarette filter was packed in a cartridge, and the SPE procedure was conducted as usual. When $100 \mathrm{~mL}$ of water was percolated through the cartridge, the recoveries of all the target analytes 
were greater than $76 \%$ and comparable to those obtained with a $\mathrm{C}_{18}$ sorbent. The method provided suitable limits of detection to monitor their presence in the samples analyzed [111].

\subsection{Ionic Liquids-Based Sorbents}

Supported ILs (SILs) and polymeric ILs (PILs) that provide hydrogen bonding, dipole-dipole, and ionic interactions with the analytes have also been used as SPE materials. Silica particles modified with N-methylimidazolium L-prolate (NMIM-Pro@SiO ${ }_{2}$ ) are an example of a SIL. NMIM-Pro@SiO 2 was applied for the extraction of polyphenols from green tea leaves and showed a high sorption capacity and selectivity [112]. Post-modification of polymeric supports such as VBC-DVB with $\mathrm{N}$-methylimidazolium was also proposed and applied as SPE sorbent for the extraction of a group of pharmaceuticals through the ion-exchange interactions that take place between the sorbent and the analytes [113].

Another approach is to prepare a PIL composed of IL-based monomers. For example, a series of 2-acrylamido-2-methyl propane sulfonate [AMPS ${ }^{-}$] combined with imidazolium $\left[\mathrm{IM}^{+}\right.$], phenylimidazolium $\left[\mathrm{PhIM}^{+}\right]$, butylimidazolium $\left[\mathrm{BuIM}^{+}\right]$and $\mathrm{N}, \mathrm{N}$-methylenebisacrylamide (MBAA) as crosslinkers was prepared and applied in protein adsorption experiments [114]. Figure 8 shows a schematic illustration of the preparation of these PIL materials. In another example, 1-vinyl-3-butylimidazolium chloride was copolymerized with EDMA to prepare a MIP selective for chlorsulfuron [115]. This MIP was further evaluated to determine chlorsulfuron from water samples by on-line SPE-LC-UV and achieved recoveries greater than $80 \%$. Several other examples of ILs as materials for SPE can be found in reviews of the subject $[116,117]$.

a) Synthesis of anionic polymeric ionic liquids monomers

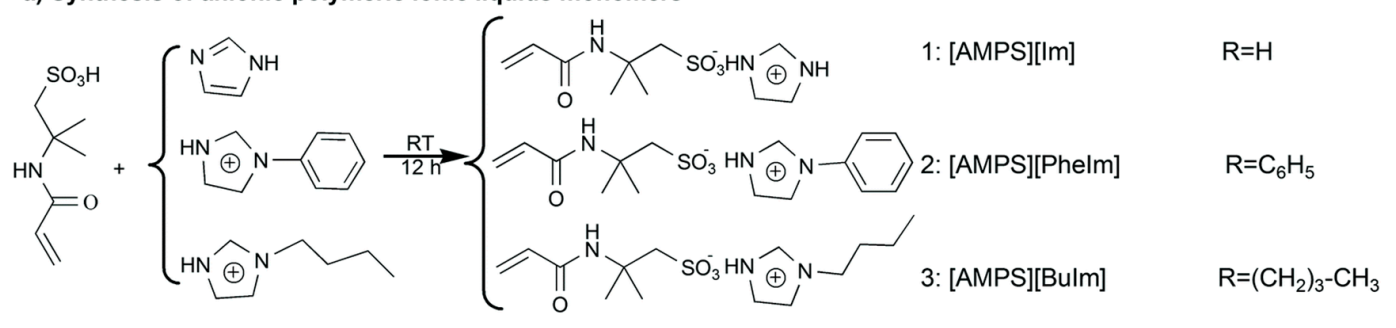

b) Preparation of anionic polymeric ionic liquids (PILs) materials

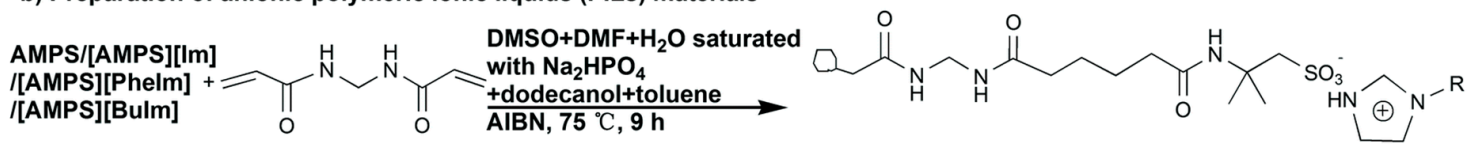

Figure 8. Examples of the schematic illustration of the preparation of polymeric ionic liquid (PIL) materials, reproduced from [114] with e permission from The Royal Society of Chemistry, 2017.

\subsection{Electrospun Nanofibers}

Electrospun nanofibers (NFs) generated using the electrospinning technique (which produces polymers with nanoscale fibrous structures) have a high SSA with various chemical properties thanks to pre- or post-electrospinning modification processes. Most of the electrospun nanofibers used in SPE are based on either PS (low mechanical strength) or Nylon-6 (high mechanical strength). PS was used to prepare electrospun NFs with the resulting material evaluated in packed-fiber SPE $(0.3 \mathrm{mg}$ of PS NFs packed in a $200 \mu \mathrm{L}$ pipette tip) mode for the extraction of Trazadone from a plasma sample. This approach is claimed to be cost- and time-effective, as well as, selective and sensitive [118]. In order to enhance the features of NFs, their combination with polymers has also been explored. For example, Bagheri et al. [119] developed a blend of polypyrrole and Nylon-6, which combines the $\pi-\pi$ interactions promoted by polypyrrole as well as the polar interaction promoted by Nylon- 6 . The polypyrrole/Nylon- 6 composite was applied in $\mu \mathrm{SPE}$ to isolate malathion from aqueous samples. The method that includes $\mu$ SPE followed by GC-MS proved to be quite good, providing sufficient 
sensitivity and good reproducibility. More details on the preparation of NFs and their application as SPE materials can be found in reviews on this subject $[120,121]$.

Apart from the materials described in the previous sections, other materials have also been developed. However, they are not described in the present review because their main application involves other sorptive microextraction techniques, such as SPME, SBSE, and MEPS instead of SPE, which is the sorptive technique explored in this review. Readers can consult other reviews or book chapters that cover these subjects more thoroughly.

\section{Conclusions}

The research in the development of different materials for SPE classically categorized as silica-based, carbon-based, and polymer-based is a continuously evolving field to improve their chemical and morphological features.

Apart from the traditional material developments, other new materials such as organic-inorganic hybrid materials, carbon nanomaterials, metallic nanoparticles, metal-organic frameworks, among others, have been recently introduced and successfully applied as SPE materials.

In view of the emergence of novel materials in recent years, as well as those already well established for years, it should be anticipated that advances in sorbent technology for SPE in particular-and sorptive extraction techniques in general—could become a never-ending field of research.

Funding: The authors would like to thank the Ministerio de Economía, Industria y Competitividad, the Agencia Estatal de Investigación, and the European Regional Development Fund (ERDF) (Project: CTQ2017-88548-P) for the financial support received.

Conflicts of Interest: The authors declare no conflict of interest.

\section{Abbreviations}

$\begin{array}{ll}\text { 1,4-PDBA } & \text { 1,4-phenyldiboric acid } \\ \text { 2-AMPS } & \text { 2-acrylamido-2-methyl propane sulfonate } \\ \text { 3-APTNS } & \text { 3-aminopropyltrimethoxysilane } \\ \text { 4VP } & \text { 4-vinylpyridine } \\ \text { BTEX } & \text { benzene, toluene, ethylbenzene, and xylene } \\ \text { BuIM } & \text { butylimidazolium } \\ \text { CE } & \text { capillary electrophoresis } \\ \text { CNTs } & \text { carbon nanotubes } \\ \text { DAD } & \text { diode array detector } \\ \text { DEAEMA } & \text { 2-(diethylamino)ethyl methacrylate } \\ \text { DMEA } & \text { N,N-dimethylethanolamine } \\ \text { dSPE } & \text { dispersive solid-phase extraction } \\ \text { DVB } & \text { divinylbenzene } \\ \text { EDCs } & \text { endocrine disrupting compounds } \\ \text { EDMA } & \text { ethylenglycol dimethacrylate } \\ \text { EME } & \text { eletromembrane extraction } \\ \text { FDU } & \text { Fudan University } \\ \text { FL } & \text { fluorescence detector } \\ \text { G } & \text { graphene } \\ \text { GC } & \text { gas chromatography } \\ \text { GCB } & \text { graphitized carbon blacks } \\ \text { GMA } & \text { glycidyl methacrylate } \\ \text { GO } & \text { graphene oxide } \\ \text { GOF } & \text { graphene oxide framework } \\ \text { HEMA } & \text { 2-hydroxyethyl methacrylate } \\ \text { HKUST } & \text { Hong Kong University of Science and Technology } \\ \text { HMS } & \text { hexagonal mesoporous silica } \\ \end{array}$


HXL hypercrosslinked

ILs ionic liquids

IM imidazolium

IMS ion mobility spectrometry

KIT-6 KoreaAdvanced Institute of Science and Technology-6

LC liquid chromatography

LDHs layered double hydroxides

MAA methaacrylic acid

MALDI matrix assisted laser desorption

MBAA N,N-methylenebisacrylamide

MCM Mobile Composition of Matter

MEPS microextraction by packed syringe

MIL materials of Institute Lavoisier

MIPs molecularly imprinted polymers

MMT montmorillonite

MNPs magnetic nanoparticles

MOFs metal-organic frameworks

MS mass spectrometry

MS/MS tandem mass spectrometry

MSPE magnetic solid-phase extraction

MTMOS methyltrimethoxysilane

MWCNTs multi-walled carbon nanotubes

NFs nanofibers

NMA N-methylolacrylamide

NMIM N-methylimidazolium

NPs nanoparticles

NSAIDs nonsteroidal anti-inflammatory drugs

NVIm N-vinylimidazole

NVP N-vinylpyrrolidone

PAHs polycyclic aromatic hydrocarbons

PBDEs polybrominated diphenyl ethers

PCBs polychlorinated bisphenyls

PETRA pentaerythritol triacrylate

PFAS perfluoroalkyl substances

PFCAs polyfluorinated carboxylic acids

PGC porous graphitic carbon

PhIM phenylimidazolium

PILs polymeric ILs

PS polystyrene

QTOF quadrupole time of flight

rGO reduced graphene oxide

SAX strong anion exchanger

SBA Santa Barbara Amorphous

SBSE stir bar sorptive extraction

SCX strong cation exchanger

SILs supported ILs

SPE solid-phase extraction

SPME solid-phase microextraction

SSA specific surface area

SWCNTs single-walled carbon nanotubes

TEOS tetraethoxysilane

TEPS triethoxyphenylsilane

TMOS tetramethoxysilane

TOF time-of-flight

$\mathrm{UiO} \quad$ University of Oslo 


$\begin{array}{ll}\text { UV } & \text { ultraviolet } \\ \text { UVM } & \text { Universidad Valencia mesoporous } \\ \text { VBC } & \text { vinylbenzyl chloride } \\ \text { WAX } & \text { weak anion exchanger } \\ \text { WCX } & \text { weak cation exchanger } \\ \text { ZIF } & \text { zeolite imidazole framework }\end{array}$

\section{References}

1. Poole, C.F. Handbooks in Separation Science: Extraction: Solid-Phase Extraction, 1st ed.; Poole, C.F., Ed.; Elsevier: Amsterdam, The Netherlands, 2020; ISBN 978-0-12-816906-3.

2. Fontanals, N.; Marcé, R.M.; Borrull, F. Porous polymer sorbents. In Handbooks of Separation Science: Extraction: Solid-Phase Extraction; Poole, C.F., Ed.; Elsevier: Amsterdam, The Netherlands, 2020; pp. 55-82, ISBN 978-0-12-816906-3.

3. Carrasco-Correa, E.J.; Vergara-Barberán, M.; Simó-Alfonso, E.F.; Herrero-Martínez, J.M. Smart Materials for Solid-Phase Extraction Applications. In Handbook of Smart Materials in Analytical Chemistry; John Wiley \& Sons, Ltd.: Hoboken, NJ, USA, 2019; pp. 531-580, ISBN 9781119422587.

4. Nazario, C.E.D.; Fumes, B.H.; da Silva, M.R.; Lanças, F.M. New materials for sample preparation techniques in bioanalysis. J. Chromatogr. B 2017, 1043, 81-95. [CrossRef] [PubMed]

5. Fontanals, N. Application of novel materials in sample treatment and separation. Cleanup and chromatographic improvements. In Chromatographic Analysis of the Environment: Mass Spectrometry Based Approaches, 4th ed.; Nollet, L., Lambropoulou, D., Eds.; CRC Press: New York, NY, USA, 2017; pp. 197-218, ISBN 9781466597563.

6. Postigo, C.; López de Alda, M.J.; Barceló, D. Fully automated determination in the low nanogram per liter level of different classes of drugs of abuse in sewage water by on-line solid-phase extraction-liquid chromatography-electrospray-tandem mass spectrometry. Anal. Chem. 2008, 80, 3123-3134. [CrossRef] [PubMed]

7. Karageorgou, E.; Myridakis, A.; Stephanou, E.G.; Samanidou, V. Multiresidue LC-MS/MS analysis of cephalosporins and quinolones in milk following ultrasound-assisted matrix solid-phase dispersive extraction combined with the quick, easy, cheap, effective, rugged, and safe methodology. J. Sep. Sci. 2013, 36, 2020-2027. [CrossRef] [PubMed]

8. Babić, S.; Mutavdžić Pavlović, D.; Ašperger, D.; Periša, M.; Zrnčić, M.; Horvat, A.J.M.; Kaštelan-Macan, M. Determination of multi-class pharmaceuticals in wastewater by liquid chromatography-tandem mass spectrometry (LC-MS-MS). Anal. Bioanal. Chem. 2010, 398, 1185-1194. [CrossRef] [PubMed]

9. Ordóñez, E.Y.; Quintana, J.B.; Rodil, R.; Cela, R. Determination of artificial sweeteners in water samples by solid-phase extraction and liquid chromatography-tandem mass spectrometry. J. Chromatogr. A 2012, 1256, 197-205. [CrossRef] [PubMed]

10. Tak, Y.H.; Toraño, J.S.; Somsen, G.W.; de Jong, G.J. Optimization of in-line fritless solid-phase extraction for capillary electrophoresis-mass spectrometry. J. Chromatogr. A 2012, 1267, 138-143. [CrossRef]

11. Azzouz, A.; Rascón, A.J.; Ballesteros, E. Simultaneous determination of parabens, alkylphenols, phenylphenols, bisphenol A and triclosan in human urine, blood and breast milk by continuous solid-phase extraction and gas chromatography-mass spectrometry. J. Pharm. Biomed. Anal. 2016, 119, 16-26. [CrossRef]

12. Zeinali, S.; Khalilzadeh, M.; Bagheri, H. Generic extraction medium: From highly polar to non-polar simultaneous determination. Anal. Chim. Acta 2019, 1066,1-12. [CrossRef]

13. Masqué, N.; Galià, M.; Marcé, R.M.; Borrull, F. New chemically modified polymeric resin for solid-phase extraction of pesticides and phenolic compounds from water. J. Chromatogr. A 1998, 803, 147-155. [CrossRef]

14. Fontanals, N.; Galià, M.; Marcé, R.M.; Borrull, F. Solid-phase extraction of polar compounds with hydrophilic copolymer sorbent. J. Chromatogr. A 2004, 1030, 63-68. [CrossRef]

15. Roy, K.S.; Purohit, A.K.; Chandra, B.; Goud, D.R.; Pardasani, D.; Dubey, D.K. Polymeric Sorbent with Controlled Surface Polarity: An Alternate for Solid-Phase Extraction of Nerve Agents and Their Markers from Organic Matrix. Anal. Chem. 2018, 90, 7025-7032. [CrossRef] [PubMed] 
16. Fontanals, N.; Marcé, R.M.; Cormack, P.A.G.; Sherrington, D.C.; Borrull, F. Monodisperse, hypercrosslinked polymer microspheres as tailor-made sorbents for highly efficient solid-phase extractions of polar pollutants from water samples. J. Chromatogr. A 2008, 1191, 118-124. [CrossRef] [PubMed]

17. Bratkowska, D.; Fontanals, N.; Cormack, P.A.G.; Sherrington, D.C.; Borrull, F.; Marcé, R.M. Hydrophilic hypercrosslinked sorbents for the solid-phase extraction of polar contaminants from water. J. Chromatogr. A 2010, 1217, 3238-3243. [CrossRef]

18. Chen, L.; Zhang, X.; Xu, Y.; Du, X.; Sun, X.; Sun, L.; Wang, H.; Zhao, Q.; Yu, A.; Zhang, H.; et al. Determination of fluoroquinolone antibiotics in environmental water samples based on magnetic molecularly imprinted polymer extraction followed by liquid chromatography-tandem mass spectrometry. Anal. Chim. Acta 2010, 662, 31-38. [CrossRef] [PubMed]

19. Michailof, C.; Manesiotis, P.; Panayiotou, C. Synthesis of caffeic acid and p-hydroxybenzoic acid molecularly imprinted polymers and their application for the selective extraction of polyphenols from olive mill waste waters. J. Chromatogr. A 2008, 1182, 25-33. [CrossRef]

20. Yang, J.; Li, Y.; Huang, C.; Jiao, Y.; Chen, J. A Phenolphthalein-Dummy Template Molecularly Imprinted Polymer for Highly Selective Extraction and Clean-Up of Bisphenol A in Complex Biological, Environmental and Food Samples. Polymer 2018, 10, 1150. [CrossRef]

21. Moein, M.M.; Javanbakht, M.; Akbari-adergani, B. Molecularly imprinted polymer cartridges coupled on-line with high performance liquid chromatography for simple and rapid analysis of human insulin in plasma and pharmaceutical formulations. Talanta 2014, 121, 30-36. [CrossRef]

22. Song, X.; Li, J.; Xu, S.; Ying, R.; Ma, J.; Liao, C.; Liu, D.; Yu, J.; Chen, L. Determination of 16 polycyclic aromatic hydrocarbons in seawater using molecularly imprinted solid-phase extraction coupled with gas chromatography-mass spectrometry. Talanta 2012, 99, 75-82. [CrossRef]

23. Gilart, N.; Marcé, R.M.; Borrull, F.; Fontanals, N. Determination of pharmaceuticals in wastewaters using solid-phase extraction-liquid chromatography-tandem mass spectrometry. J. Sep. Sci. 2012, 35, 875-882. [CrossRef]

24. Moreno-González, D.; Hamed, A.M.; García-Campaña, A.M.; Gámiz-Gracia, L. Evaluation of hydrophilic interaction liquid chromatography-tandem mass spectrometry and extraction with molecularly imprinted polymers for determination of aminoglycosides in milk and milk-based functional foods. Talanta 2017, 171, 74-80. [CrossRef]

25. Roszko, M.; Szymczyk, K.; Jędrzejczak, R. Simultaneous separation of chlorinated/brominated dioxins, polychlorinated biphenyls, polybrominated diphenyl ethers and their methoxylated derivatives from hydroxylated analogues on molecularly imprinted polymers prior to gas/liquid chromatography and ma. Talanta 2015, 144, 171-183. [CrossRef] [PubMed]

26. Castiglioni, S.; Bagnati, R.; Melis, M.; Panawennage, D.; Chiarelli, P.; Fanelli, R.; Zuccato, E. Identification of cocaine and its metabolites in urban wastewater and comparison with the human excretion profile in urine. Water Res. 2011, 45, 5141-5150. [CrossRef] [PubMed]

27. Tomková, J.; Ondra, P.; Válka, I. Simultaneous determination of mushroom toxins $\alpha$-amanitin, $\beta$-amanitin and muscarine in human urine by solid-phase extraction and ultra-high-performance liquid chromatography coupled with ultra-high-resolution TOF mass spectrometry. Forensic Sci. Int. 2015, 251, 209-213. [CrossRef] [PubMed]

28. Janda, J.; Nödler, K.; Brauch, H.-J.; Zwiener, C.; Lange, F.T. Robust trace analysis of polar (C2-C8) perfluorinated carboxylic acids by liquid chromatography-tandem mass spectrometry: Method development and application to surface water, groundwater and drinking water. Environ. Sci. Pollut. Res. 2019, 26, 7326-7336. [CrossRef]

29. Zhang, P.; Bui, A.; Rose, G.; Allinson, G. Mixed-mode solid-phase extraction coupled with liquid chromatography tandem mass spectrometry to determine phenoxy acid, sulfonylurea, triazine and other selected herbicides at nanogram per litre levels in environmental waters. J. Chromatogr. A 2014, 1325, 56-64. [CrossRef]

30. Fontanals, N.; Cormack, P.A.G.; Sherrington, D.C. Hypercrosslinked polymer microspheres with weak anion-exchange character. Preparation of the microspheres and their applications $\mathrm{pH}$-tunable, selective extractions of analytes from complex environmental samples. J. Chromatogr. A 2008, 1215, 21-29. [CrossRef]

31. Bratkowska, D.; Marcé, R.M.; Cormack, P.A.G.; Sherrington, D.C.; Borrull, F.; Fontanals, N. Synthesis and application of hypercrosslinked polymers with weak cation-exchange character for the selective extraction of basic pharmaceuticals from complex environmental samples. J. Chromatogr. A 2010, 1217, 1575-1582. [CrossRef] 
32. Huang, C.; Li, Y.; Yang, J.; Peng, J.; Tan, J.; Fan, Y.; Wang, L.; Chen, J. Hyperbranched mixed-mode anion-exchange polymeric sorbent for highly selective extraction of nine acidic non-steroidal anti-inflammatory drugs from human urine. Talanta 2018, 190, 15-22. [CrossRef]

33. Hu, K.; Zhao, G.; Liu, J.; Jia, L.; Xie, F.; Zhang, S.; Liu, H.; Liu, M. Simultaneous quantification of three alkylated-purine adducts in human urine using sulfonic acid poly(glycidyl methacrylate-divinylbenzene)-based microspheres as sorbent combined with LC-MS/MS. J. Chromatogr. B 2018, 1081-1082, 15-24. [CrossRef]

34. Hernández, F.; Ibáñez, M.; Botero-Coy, A.-M.; Bade, R.; Bustos-López, M.C.; Rincón, J.; Moncayo, A.; Bijlsma, L. LC-QTOF MS screening of more than 1000 licit and illicit drugs and their metabolites in wastewater and surface waters from the area of Bogotá, Colombia. Anal. Bioanal. Chem. 2015, 407, 6405-6416. [CrossRef]

35. Fontanals, N.; Puig, P.; Galià, M.; Marcé, R.M.; Borrull, F. New hydrophilic polymeric resin based on 4-vinylpyridine-divinylbenzene for solid-phase extraction of polar compounds from water. J. Chromatogr. A 2004, 1035, 281-284. [CrossRef] [PubMed]

36. Fontanals, N.; Marcé, R.M.; Borrull, F.; Cormack, P.A.G. Hypercrosslinked materials: Preparation, characterisation and applications. Polym. Chem. 2015, 6, 7231-7244. [CrossRef]

37. Speltini, A.; Scalabrini, A.; Maraschi, F.; Sturini, M.; Profumo, A. Newest applications of molecularly imprinted polymers for extraction of contaminants from environmental and food matrices: A review. Anal. Chim. Acta 2017, 974, 1-26. [CrossRef] [PubMed]

38. Martín-Esteban, A. Molecularly-imprinted polymers as a versatile, highly selective tool in sample preparation. TrAC Trends Anal. Chem. 2013, 45, 169-181. [CrossRef]

39. Sellergren, B. Direct drug determination by selective sample enrichment on an imprinted polymer. Anal. Chem. 1994, 66, 1578-1582. [CrossRef]

40. Fontanals, N.; Cormack, P.A.G.; Marcé, R.M.; Borrull, F. Mixed-mode ion-exchange polymeric sorbents: Dual-phase materials that improve selectivity and capacity. Trends Anal. Chem. 2010, 29, 765-779. [CrossRef]

41. Khezeli, T.; Daneshfar, A. Development of dispersive micro-solid phase extraction based on micro and nano sorbents. TrAC Trends Anal. Chem. 2017, 89, 99-118. [CrossRef]

42. Maciel, E.V.S.; de Toffoli, A.L.; Neto, E.S.; Nazario, C.E.D.; Lanças, F.M. New materials in sample preparation: Recent advances and future trends. TrAC Trends Anal. Chem. 2019, 119, 115633. [CrossRef]

43. Ng, N.-T.; Kamaruddin, A.F.; Wan Ibrahim, W.A.; Sanagi, M.M.; Abdul Keyon, A.S. Advances in organic-inorganic hybrid sorbents for the extraction of organic and inorganic pollutants in different types of food and environmental samples. J. Sep. Sci. 2018, 41, 195-208. [CrossRef]

44. Ibrahim, W.A.W.; Veloo, K.V.; Sanagi, M.M. Novel sol-gel hybrid methyltrimethoxysilane-tetraethoxysilane as solid phase extraction sorbent for organophosphorus pesticides. J. Chromatogr. A 2012, 1229, 55-62. [CrossRef]

45. Bagheri, H.; Piri-Moghadam, H.; Rastegar, S.; Taheri, N. Electrospun titania sol-gel-based ceramic composite nanofibers for online micro- solid-phase extraction with high-performance liquid chromatography. J. Sep. Sci. 2014, 37, 1982-1988. [CrossRef] [PubMed]

46. Abd Rahim, M.; Wan Ibrahim, W.A.; Ramli, Z.; Sanagi, M.M.; Aboul-Enein, H.Y. New Sol-gel hybrid material in solid phase extraction combined with liquid chromatography for the determination of non-steroidal anti-inflammatory drugs in water samples. Chromatographia 2016, 79, 421-429. [CrossRef]

47. Mauri-Aucejo, A.; Amorós, P.; Moragues, A.; Guillem, C.; Belenguer-Sapiña, C. Comparison of the solid-phase extraction efficiency of a bounded and an included cyclodextrin-silica microporous composite for polycyclic aromatic hydrocarbons determination in water samples. Talanta 2016, 156-157, 95-103. [CrossRef] [PubMed]

48. Zhang, W.; Du, J.; Su, C.; Zhu, L.; Chen, Z. Development of $\beta$-cyclodextrin-modified silica and polyporous polymer particles for solid-phase extraction of methyl jasmonate in aqueous and plant samples. Anal. Lett. 2013, 46, 900-911. [CrossRef]

49. Yang, Y.; Li, Q.; Fang, G.; Wang, S. Preparation and evaluation of novel surface molecularly imprinted polymers by sol-gel process for online solid-phase extraction coupled with high performance liquid chromatography to detect trace patulin in fruit derived products. RSC Adv. 2016, 6, 54510-54517. [CrossRef]

50. Kechagia, M.; Samanidou, V.; Kabir, A.; Furton, K.G. One-pot synthesis of a multi-template molecularly imprinted polymer for the extraction of six sulfonamide residues from milk before high-performance liquid chromatography with diode array detection. J. Sep. Sci. 2018, 41, 723-731. [CrossRef] 
51. Ou-Yang, C.-F.; Liu, J.-Y.; Kao, H.-M.; Wang, J.-H.; Liu, S.-P.; Wang, J.-L. Analysis of polycyclic aromatic hydrocarbons using porous material MCM-41 as a sorbent. Anal. Methods 2013, 5, 6874-6880. [CrossRef]

52. Gañán, J.; Morante-Zarcero, S.; Pérez-Quintanilla, D.; Marina, M.L.; Sierra, I. One-pot synthesized functionalized mesoporous silica as a reversed-phase sorbent for solid-phase extraction of endocrine disrupting compounds in milks. J. Chromatogr. A 2016, 1428, 228-235. [CrossRef]

53. Li, Y.; Huang, C.; Yang, J.; Peng, J.; Jin, J.; Ma, H.; Chen, J. Multifunctionalized mesoporous silica as an efficient reversed-phase/anion exchange mixed-mode sorbent for solid-phase extraction of four acidic nonsteroidal anti-inflammatory drugs in environmental water samples. J. Chromatogr. A 2017, 1527, 10-17. [CrossRef]

54. Zhang, Z.; Li, L.; Wang, H.; Guo, L.; Zhai, Y.; Zhang, J.; Yang, Y.; Wang, H.; Yin, Z.; Lu, Y. Preparation of molecularly imprinted ordered mesoporous silica for rapid and selective separation of trace bisphenol A from water samples. Appl. Surf. Sci. 2018, 448, 380-388. [CrossRef]

55. Li, Y.; Yang, J.; Huang, C.; Wang, L.; Wang, J.; Chen, J. Dendrimer-functionalized mesoporous silica as a reversed-phase/anion-exchange mixed-mode sorbent for solid phase extraction of acid drugs in human urine. J. Chromatogr. A 2015, 1392, 28-36. [CrossRef] [PubMed]

56. Pellicer-Castell, E.; Belenguer-Sapiña, C.; Amorós, P.; Haskouri, J.E.; Herrero-Martínez, J.M.; Mauri-Aucejo, A. Study of silica-structured materials as sorbents for organophosphorus pesticides determination in environmental water samples. Talanta 2018, 189, 560-567. [CrossRef] [PubMed]

57. Tang, S.; Lee, H.K. Application of dissolvable layered double hydroxides as sorbent in dispersive solid-phase extraction and extraction by co-precipitation for the determination of aromatic acid anions. Anal. Chem. 2013, 85, 7426-7433. [CrossRef] [PubMed]

58. Alsharaa, A.; Sajid, M.; Basheer, C.; Alhooshani, K.; Lee, H.K. Determination of haloacetic acids in water using layered double hydroxides as a sorbent in dispersive solid-phase extraction followed by liquid chromatography with tandem mass spectrometry. J. Sep. Sci. 2016, 39, 3610-3615. [CrossRef] [PubMed]

59. Seidi, S.; Sanàti, S.E. Nickel-iron layered double hydroxide nanostructures for micro solid phase extraction of nonsteroidal anti-inflammatory drugs, followed by quantitation by HPLC-UV. Microchim. Acta 2019, 186, 297. [CrossRef]

60. Shamsayei, M.; Yamini, Y.; Asiabi, H. Evaluation of highly efficient on-line yarn-in-tube solid phase extraction method for ultra-trace determination of chlorophenols in honey samples. J. Chromatogr. A 2018, 1569, 70-78. [CrossRef]

61. Cai, Q.; Zhao, T.; Zhang, L.; Zhao, P.; Zhu, Y.; Xu, H.; Hou, X. A new strategy for extraction and depuration of pantoprazole in rat plasma: Vortex assisted dispersive micro-solid-phase extraction employing metal organic framework MIL-101(Cr) as sorbent followed by dispersive liquid-liquid microextraction based on soli. J. Pharm. Biomed. Anal. 2019, 172, 86-93. [CrossRef]

62. Chen, Z.; Yu, C.; Xi, J.; Tang, S.; Bao, T.; Zhang, J. A hybrid material prepared by controlled growth of a covalent organic framework on amino-modified MIL-68 for pipette tip solid-phase extraction of sulfonamides prior to their determination by HPLC. Microchim. Acta 2019, 186, 393. [CrossRef]

63. Ge, D.; Lee, H.K. Water stability of zeolite imidazolate framework 8 and application to porous membrane-protected micro-solid-phase extraction of polycyclic aromatic hydrocarbons from environmental water samples. J. Chromatogr. A 2011, 1218, 8490-8495. [CrossRef]

64. Mohammadnejad, M.; Gudarzi, Z.; Geranmayeh, S.; Mahdavi, V. HKUST-1 metal-organic framework for dispersive solid phase extraction of 2-methyl-4-chlorophenoxyacetic acid (MCPA) prior to its determination by ion mobility spectrometry. Microchim. Acta 2018, 185, 495. [CrossRef]

65. Rocío-Bautista, P.; Martínez-Benito, C.; Pino, V.; Pasán, J.; Ayala, J.H.; Ruiz-Pérez, C.; Afonso, A.M. The metal-organic framework HKUST-1 as efficient sorbent in a vortex-assisted dispersive micro solid-phase extraction of parabens from environmental waters, cosmetic creams, and human urine. Talanta 2015, 139, 13-20. [CrossRef] [PubMed]

66. Pang, X.; Liu, H.; Yu, H.; Zhang, M.; Bai, L.; Yan, H. A metal organic framework polymer monolithic column as a novel adsorbent for on-line solid phase extraction and determination of ursolic acid in Chinese herbal medicine. J. Chromatogr. B 2019, 1125, 121715. [CrossRef] [PubMed]

67. Qu, F.; Xia, L.; Wu, C.; Liu, L.; Li, G.; You, J. Sensitive and accurate determination of sialic acids in serum with the aid of dispersive solid-phase extraction using the zirconium-based MOF of UiO-66-NH2 as sorbent. RSC Adv. 2016, 6, 64895-64901. [CrossRef] 
68. Kabir, A.; Furton, K.G.; Malik, A. Innovations in sol-gel microextraction phases for solvent-free sample preparation in analytical chemistry. TrAC Trends Anal. Chem. 2013, 45, 197-218. [CrossRef]

69. Casado, N.; Pérez-Quintanilla, D.; Morante-Zarcero, S.; Sierra, I. Current development and applications of ordered mesoporous silicas and other sol-gel silica-based materials in food sample preparation for xenobiotics analysis. TrAC Trends Anal. Chem. 2017, 88, 167-184. [CrossRef]

70. Pal, N.; Cho, E.-B.; Patra, A.K.; Kim, D. Ceria-Containing Ordered Mesoporous Silica: Synthesis, Properties, and Applications. Chem CatChem 2016, 8, 285-303. [CrossRef]

71. Maya, F.; Palomino Cabello, C.; Ghani, M.; Turnes Palomino, G.; Cerdà, V. Emerging materials for sample preparation. J. Sep. Sci. 2018, 41, 262-287. [CrossRef] [PubMed]

72. Bi, X.; Zhang, H.; Dou, L. Layered double hydroxide-based nanocarriers for drug delivery. Pharmaceutics 2014, 6, 298-332. [CrossRef]

73. Sajid, M.; Basheer, C. Layered double hydroxides: Emerging sorbent materials for analytical extractions. TrAC Trends Anal. Chem. 2016, 75, 174-182. [CrossRef]

74. Wang, Y.; Rui, M.; Lu, G. Recent applications of metal-organic frameworks in sample pretreatment. J. Sep. Sci. 2018, 41, 180-194. [CrossRef]

75. Xiang, Z.; Cao, D.; Lan, J.; Wang, W.; Broom, D.P. Multiscale simulation and modelling of adsorptive processes for energy gas storage and carbon dioxide capture in porous coordination frameworks. Energy Environ. Sci. 2010, 3, 1469-1487. [CrossRef]

76. Andersson, S.; Larsson, P.-E. Atomic-scale modeling of hydrogen storage in the UiO-66 and UiO-67 metal-organic frameworks. Microporous Mesoporous Mater. 2016, 224, 349-359. [CrossRef]

77. Du, F.; Qin, Q.; Deng, J.; Ruan, G.; Yang, X.; Li, L.; Li, J. Magnetic metal-organic framework MIL-100(Fe) microspheres for the magnetic solid-phase extraction of trace polycyclic aromatic hydrocarbons from water samples. J. Sep. Sci. 2016, 39, 2356-2364. [CrossRef] [PubMed]

78. del Rio, M.; Palomino Cabello, C.; González, V.; Maya, F.; Parra, J.B.; Cerdà, V.; Turnes Palomino, G. Metal oxide assisted preparation of core-shell beads with dense metal-organic framework coatings for the enhanced extraction of organic pollutants. Chem. A Eur. J. 2016, 22, 11770-11777. [CrossRef] [PubMed]

79. Azzouz, A.; Kailasa, S.K.; Lee, S.S.; Rascón, A.J.; Ballesteros, E.; Zhang, M.; Kim, K.-H. Review of nanomaterials as sorbents in solid-phase extraction for environmental samples. TrAC Trends Anal. Chem. 2018, 108, 347-369. [CrossRef]

80. Płotka-Wasylka, J.; Szczepańska, N.; de la Guardia, M.; Namieśnik, J. Modern trends in solid phase extraction: New sorbent media. TrAC Trends Anal. Chem. 2016, 77, 23-43. [CrossRef]

81. Yu, P.; Wang, Q.; Zhang, X.; Zhang, X.; Shen, S.; Wang, Y. Development of superparamagnetic high-magnetization C18-functionalized magnetic silica nanoparticles as sorbents for enrichment and determination of methylprednisolone in rat plasma by high performance liquid chromatography. Anal. Chim. Acta 2010, 678, 50-55. [CrossRef]

82. Eskandari, H.; Naderi-Darehshori, A. Preparation of magnetite/poly (styrene-divinylbenzene) nanoparticles for selective enrichment-determination of fenitrothion in environmental and biological samples. Anal. Chim. Acta 2012, 743, 137-144. [CrossRef]

83. Asgharinezhad, A.A.; Ebrahimzadeh, H.; Mirbabaei, F.; Mollazadeh, N.; Shekari, N. Dispersive micro-solid-phase extraction of benzodiazepines from biological fluids based on polyaniline/magnetic nanoparticles composite. Anal. Chim. Acta 2014, 844, 80-89. [CrossRef]

84. Asgharinezhad, A.A.; Karami, S.; Ebrahimzadeh, H.; Shekari, N.; Jalilian, N. Polypyrrole/magnetic nanoparticles composite as an efficient sorbent for dispersive micro-solid-phase extraction of antidepressant drugs from biological fluids. Int. J. Pharm. 2015, 494, 102-112. [CrossRef]

85. Madrakian, T.; Fazl, F.; Ahmadi, M.; Afkhami, A. Efficient solid phase extraction of codeine from human urine samples using a novel magnetic molecularly imprinted nanoadsorbent and its spectrofluorometric determination. New J. Chem. 2016, 40, 122-129. [CrossRef]

86. Zhang, Y.; Lee, H.K. Liquid phase microextraction using knitting wool as the extractant phase holder before chromatographic analysis: A new approach for trace analysis. J. Chromatogr. A 2013, 1273, 12-17. [CrossRef] [PubMed]

87. Zhou, Q.; Lei, M.; Li, J.; Zhao, K.; Liu, Y. Sensitive determination of bisphenol A, 4-nonylphenol and 4-octylphenol by magnetic solid phase extraction with Fe@MgAl-LDH magnetic nanoparticles from environmental water samples. Sep. Purif. Technol. 2017, 182, 78-86. [CrossRef] 
88. Rodríguez, J.A.; Ibarra, I.S.; Miranda, J.M.; Barrado, E.; Santos, E.M. Magnetic solid phase extraction based on fullerene and activated carbon adsorbents for determination of azo dyes in water samples by capillary electrophoresis. Anal. Methods 2016, 8, 8466-8473. [CrossRef]

89. Zhang, H.-F.; Shi, Y.-P. Preparation of Fe3O4 nanoparticle enclosure hydroxylated multi-walled carbon nanotubes for the determination of aconitines in human serum samples. Anal. Chim. Acta 2012, 724, 54-60. [CrossRef]

90. Zhu, L.; Xu, H. Magnetic graphene oxide as adsorbent for the determination of polycyclic aromatic hydrocarbon metabolites in human urine. J. Sep. Sci. 2014, 37, 2591-2598. [CrossRef]

91. Cai, M.-Q.; Su, J.; Hu, J.-Q.; Wang, Q.; Dong, C.-Y.; Pan, S.-D.; Jin, M.-C. Planar graphene oxide-based magnetic ionic liquid nanomaterial for extraction of chlorophenols from environmental water samples coupled with liquid chromatography-tandem mass spectrometry. J. Chromatogr. A 2016, 1459, 38-46. [CrossRef]

92. Liu, Q.; Shi, J.; Wang, T.; Guo, F.; Liu, L.; Jiang, G. Hemimicelles/admicelles supported on magnetic graphene sheets for enhanced magnetic solid-phase extraction. J. Chromatogr. A 2012, 1257, 1-8. [CrossRef]

93. Herrero-Latorre, C.; Barciela-García, J.; García-Martín, S.; Peña-Crecente, R.M.; Otárola-Jiménez, J. Magnetic solid-phase extraction using carbon nanotubes as sorbents: A review. Anal. Chim. Acta 2015, 892, 10-26. [CrossRef]

94. Li, M.; Jiao, C.; Yang, X.; Wang, C.; Wu, Q.; Wang, Z. Solid phase extraction of carbamate pesticides with banana peel derived hierarchical porous carbon prior to high performance liquid chromatography. Anal. Methods 2017, 9, 593-599. [CrossRef]

95. Serrano, A.; Gallego, M. Fullerenes as sorbent materials for benzene, toluene, ethylbenzene, and xylene isomers preconcentration. J. Sep. Sci. 2006, 29, 33-40. [CrossRef] [PubMed]

96. Latrous El Atrache, L.; Hachani, M.; Kefi, B.B. Carbon nanotubes as solid-phase extraction sorbents for the extraction of carbamate insecticides from environmental waters. Int. J. Environ. Sci. Technol. 2016, 13, 201-208. [CrossRef]

97. Lalović, B.; DJurkić, T.; Vukčević, M.; Janković-Častvan, I.; Kalijadis, A.; Laušević, Z.; Laušević, M. Solid-phase extraction of multi-class pharmaceuticals from environmental water samples onto modified multi-walled carbon nanotubes followed by LC-MS/MS. Environ. Sci. Pollut. Res. 2017, 24, 20784-20793. [CrossRef] [PubMed]

98. Tabani, H.; Fakhari, A.R.; Shahsavani, A.; Behbahani, M.; Salarian, M.; Bagheri, A.; Nojavan, S. Combination of graphene oxide-based solid phase extraction and electro membrane extraction for the preconcentration of chlorophenoxy acid herbicides in environmental samples. J. Chromatogr. A 2013, 1300, 227-235. [CrossRef]

99. Li, M.; Wang, J.; Jiao, C.; Wang, C.; Wu, Q.; Wang, Z. Graphene oxide framework: An adsorbent for solid phase extraction of phenylurea herbicides from water and celery samples. J. Chromatogr. A 2016, 1469, 17-24. [CrossRef]

100. Ahmadi, M.; Elmongy, H.; Madrakian, T.; Abdel-Rehim, M. Nanomaterials as sorbents for sample preparation in bioanalysis: A review. Anal. Chim. Acta 2017, 958, 1-21. [CrossRef]

101. Hou, X.; Wang, X.; Sun, Y.; Wang, L.; Guo, Y. Graphene oxide for solid-phase extraction of bioactive phenolic acids. Anal. Bioanal. Chem. 2017, 409, 3541-3549. [CrossRef]

102. Takátsy, A.; Böddi, K.; Nagy, L.; Nagy, G.; Szabó, S.; Markó, L.; Wittmann, I.; Ohmacht, R.; Ringer, T.; Bonn, G.K.; et al. Enrichment of Amadori products derived from the nonenzymatic glycation of proteins using microscale boronate affinity chromatography. Anal. Biochem. 2009, 393, 8-22. [CrossRef]

103. Caballero-Díaz, E.; Valcárcel, M. Carbon nanotubes as SPE sorbents for the extraction of salicylic acid from river water. J. Sep. Sci. 2014, 37, 434-439. [CrossRef]

104. Sun, X.; Tang, Y.; Di, D.; Guo, M.; Zhao, L. Evaluation of an efficient and selective adsorbent based on multi-walled carbon nanotubes coated silica microspheres for detecting nucleobases and nucleosides in human urine. New J. Chem. 2015, 39, 5513-5521. [CrossRef]

105. Shi, Z.; Li, Q.; Xu, D.; Huai, Q.; Zhang, H. Graphene-based pipette tip solid-phase extraction with ultra-high performance liquid chromatography and tandem mass spectrometry for the analysis of carbamate pesticide residues in fruit juice. J. Sep. Sci. 2016, 39, 4391-4397. [CrossRef] [PubMed]

106. Salehinia, S.; Ghoreishi, S.M.; Maya, F.; Cerdà, V. Hydrophobic magnetic montmorillonite composite material for the efficient adsorption and microextraction of bisphenol A from water samples. J. Environ. Chem. Eng. 2016, 4, 4062-4071. [CrossRef] 
107. Arnnok, P.; Patdhanagul, N.; Burakham, R. Dispersive solid-phase extraction using polyaniline-modified zeolite $\mathrm{NaY}$ as a new sorbent for multiresidue analysis of pesticides in food and environmental samples. Talanta 2017, 164, 651-661. [CrossRef]

108. Baile, P.; Fernández, E.; Vidal, L.; Canals, A. Zeolites and zeolite-based materials in extraction and microextraction techniques. Analyst 2019, 144, 366-387. [CrossRef] [PubMed]

109. Selman, M.H.J.; Hemayatkar, M.; Deelder, A.M.; Wuhrer, M. Cotton HILIC SPE microtips for microscale purification and enrichment of glycans and glycopeptides. Anal. Chem. 2011, 83, 2492-2499. [CrossRef]

110. Lu, Q.; Wu, J.-H.; Yu, Q.-W.; Feng, Y.-Q. Using pollen grains as novel hydrophilic solid-phase extraction sorbents for the simultaneous determination of 16 plant growth regulators. J. Chromatogr. A 2014, 1367, 39-47. [CrossRef]

111. Fang, G.; Chen, W.; Yao, Y.; Wang, J.; Qin, J.; Wang, S. Multi-residue determination of organophosphorus and organochlorine pesticides in environmental samples using solid-phase extraction with cigarette filter followed by gas chromatography-mass spectrometry. J. Sep. Sci. 2012, 35, 534-540. [CrossRef]

112. Zhang, W.; Feng, X.; Alula, Y.; Yao, S. Bionic multi-tentacled ionic liquid-modified silica gel for adsorption and separation of polyphenols from green tea (Camellia sinensis) leaves. Food Chem. 2017, 230, 637-648. [CrossRef]

113. Fontanals, N.; Ronka, S.; Borrull, F.; Trochimczuk, A.W.; Marcé, R.M. Supported imidazolium ionic liquid phases: A new material for solid-phase extraction. Talanta 2009, 80, 250-256. [CrossRef]

114. Dang, M.; Deng, Q.; Fang, G.; Zhang, D.; Liu, J.; Wang, S. Preparation of novel anionic polymeric ionic liquid materials and their potential application to protein adsorption. J. Mater. Chem. B 2017, 5, 6339-6347. [CrossRef]

115. Guo, L.; Deng, Q.; Fang, G.; Gao, W.; Wang, S. Preparation and evaluation of molecularly imprinted ionic liquids polymer as sorbent for on-line solid-phase extraction of chlorsulfuron in environmental water samples. J. Chromatogr. A 2011, 1218, 6271-6277. [CrossRef] [PubMed]

116. Clark, K.D.; Emaus, M.N.; Varona, M.; Bowers, A.N.; Anderson, J.L. Ionic liquids: Solvents and sorbents in sample preparation. J. Sep. Sci. 2018, 41, 209-235. [CrossRef] [PubMed]

117. Fontanals, N.; Borrull, F.; Marcé, R.M. Ionic liquids in solid-phase extraction. Trends Anal. Chem. 2012, 41, 15-26. [CrossRef]

118. Kang, X.; Pan, C.; Xu, Q.; Yao, Y.; Wang, Y.; Qi, D.; Gu, Z. The investigation of electrospun polymer nanofibers as a solid-phase extraction sorbent for the determination of trazodone in human plasma. Anal. Chim. Acta 2007, 587, 75-81. [CrossRef] [PubMed]

119. Bagheri, H.; Aghakhani, A.; Akbari, M.; Ayazi, Z. Electrospun composite of polypyrrole-polyamide as a micro-solid phase extraction sorbent. Anal. Bioanal. Chem. 2011, 400, 3607-3613. [CrossRef]

120. Chigome, S.; Torto, N. Electrospun nanofiber-based solid-phase extraction. TrAC Trends Anal. Chem. 2012, 38, 21-31. [CrossRef]

121. Háková, M.; Havlíková, L.C.; Solich, P.; Švec, F.; Šatínský, D. Electrospun nanofiber polymers as extraction phases in analytical chemistry-The advances of the last decade. TrAC Trends Anal. Chem. 2019, 110, 81-96. [CrossRef]

(C) 2019 by the authors. Licensee MDPI, Basel, Switzerland. This article is an open access article distributed under the terms and conditions of the Creative Commons Attribution (CC BY) license (http://creativecommons.org/licenses/by/4.0/). 